\title{
Alliance Governance Mechanisms in the Face of Disruption
}

\author{
Arne Keller, ${ }^{a}$ Fabrice Lumineau, ${ }^{b}$ Thomas Mellewigt, ${ }^{c}$ Africa Ariño ${ }^{d}$ \\ a JKU Business School, Johannes Kepler University Linz, 4040 Linz, Austria; ${ }^{\mathbf{b}}$ Faculty of Business and Economics, University of Hong Kong,

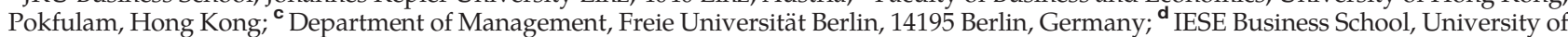 \\ Navarra, 08034 Barcelona, Spain \\ Contact: arne.keller@jku.at, (iD https://orcid.org/0000-0003-0046-0018 (AK); lumineau@hku.hk, (iD https://orcid.org/0000-0003-2194-8629 (FL); \\ thomas.mellewigt@fu-berlin.de, (D) https://orcid.org/0000-0002-9113-464X (TM); afarino@iese.edu, \\ (iD) https://orcid.org/0000-0002-5933-2400 (AA)
}

Received: May 30, 2019

Revised: March 10, 2020; October 28, 2020

Accepted: November 2, 2020

Published Online in Articles in Advance: March 5, 2021

https://doi.org/10.1287/orsc.2021.1437

Copyright: @ 2021 The Author(s)

\begin{abstract}
Existing academic literature has discussed contracts and relational governance as the key mechanisms that help alliance partners address problems of cooperation and coordination. However, when an alliance undergoes disruption, the nature and extent of such problems may change and therefore the value of these mechanisms may change. This study advances a dynamic perspective on alliance governance by examining the impact of disruption and subsequent adjustment on the value of alliance governance mechanisms. To this end, we longitudinally studied a revelatory case of a research and development alliance in the veterinary drug industry that experienced disruption triggered by an internal restructuring at one of the partner companies. We approached the evidence with a finegrained typology that builds on two dimensions that underlie governance mechanisms: the means to enforce their ruling principles (contractual versus relational) and the level of codification of these principles (formal versus informal). Based on our findings, we (1) show the significance of this revised typology, which suggests that contractual governance is not necessarily formal and relational governance is not necessarily informal; (2) provide a more systematic discussion of the tradeoffs that the various mechanisms entail and how these are altered through disruption and adjustment dynamics; and (3) analyze how the interplay between different types of governance mechanisms evolves following disruption and adjustment. Overall, our study brings the concept of disruption to the dynamic perspective of alliance governance and highlights the contingent value of alliance governance mechanisms.
\end{abstract}

Open Access Statement: This work is licensed under a Creative Commons Attribution 4.0 International License. You are free to copy, distribute, transmit and adapt this work, but you must attribute this work as "Organization Science. Copyright (c) 2021 The Author(s). https://doi.org/10.1287/orsc .2021.1437, used under a Creative Commons Attribution License: https://creativecommons.org/ licenses/by/4.0/."

Funding: This work was supported by Joaquim Molins Figueras, Chair of Strategic Alliances, IESE Business School.

Keywords: alliance governance $\cdot$ contracts $\cdot$ relational governance $\cdot$ alliance post-formation dynamics

\section{Introduction}

Despite their prevalence, alliances are intrinsically unstable and often face the risk of disruption (Das and Teng 2002, Bakker 2016), which is broadly understood as a situation in which it is difficult for the partners to continue their collaboration in the normal way. Alliance governance mechanisms are valuable to the extent that they help partners address problems of cooperation and coordination (Hoetker and Mellewigt 2009, Gulati et al. 2012, Reuer et al. 2016). However, when an alliance experiences disruption, the nature and extent of such problems may change. Therefore, how does the value of different governance mechanisms change when an alliance undergoes a disruption and subsequent adjustment?

Existing literature has primarily focused on contracts (Reuer and Ariño 2007, Poppo and Zhou 2014,
Schepker et al. 2014) and relational governance (Das and Teng 1998, Zaheer et al. 1998, Schilke and Cook 2015) as the two main types of mechanisms for governing interfirm alliances. In addition to studying the qualities and impact of each mechanism individually, prior research has paid a great deal of attention to understanding how both governance mechanisms interact to jointly affect an alliance's development and performance (Poppo and Zenger 2002, Klein Woolthuis et al. 2005, Ryall and Sampson 2009). This has led to a lively debate in the governance literature on determining whether contractual and relational mechanisms substitute or complement each other (for reviews, see Cao and Lumineau 2015, Poppo and Cheng 2018). However, although it is increasingly understood that interorganizational collaborations are unstable and subject to important changes over time 
(Majchrzak et al. 2015, Berends and Sydow 2020), only a few studies have explicitly focused on the dynamics of alliance governance mechanisms (Mayer and Argyres 2004, Faems et al. 2008).

In this paper, we extend this line of inquiry by focusing on the impact of both disruption and its subsequent adjustment on the value of alliance governance mechanisms: that is, how specific mechanisms are useful to a given alliance. Research has shown that disruption in interorganizational relationships can be caused by numerous nonroutine events, including technological and regulatory shocks (Madhavan et al. 1998), firm entry and exit from a multiparty alliance (Bakker 2016), and change of key personnel (de Rond and Bouchikhi 2004), as well as disputes about delivery or technology sharing (Zhang et al. 2018). Although disruption in strategic alliances is an important managerial phenomenon (Kale and Singh 2009) posing substantial challenges for the involved parties, it remains largely overlooked in research on governance. Both conceptual work (Schilke and Cook 2013) and in-depth longitudinal case studies (Mayer and Argyres 2004) suggest that the value of formal contracts and relational governance steadily increases over time in a relationship. However, the literature's understanding of how a disruption and its subsequent adjustment affect and potentially shift governance mechanisms' value is currently insufficient.

In order to build and extend theory on the dynamics of alliance governance mechanisms, we used the logic of qualitative inquiry (Miles and Huberman 1984, Yin 2014). Striving to gain an in-depth, processual understanding of how disruption impacts the value of an alliance's governance mechanisms, we leveraged insights from a longitudinal single-case study (Siggelkow 2007, Ozcan et al. 2017). Specifically, we examined the governance dynamics of a highly revelatory yet archetypical research and development (R\&D) alliance between a large, established pharmaceutical company and a small, entrepreneurial biotech firm. After several months of operation, this alliance was subject to a marked disruption, triggered by an internal restructuring of the larger partner, which led to severe relationship strains and ultimately to an adjustment of the cooperation. This made this alliance particularly suitable for advancing knowledge about how disruption and subsequent adjustment impact both the individual and the joint value of alliance governance mechanisms. We approached the case's evidence with a fine-grained typology of alliance governance mechanisms that is based on two dimensions: (1) the means to enforce the mechanisms' ruling principles (contractual versus relational) and (2) the level of codification of those principles (formal versus informal). Our in-depth longitudinal analysis of governance mechanisms revealed that the prevailing unidimensional distinction between contractual versus relational mechanisms proved inadequate to explain the observed dynamics. Instead, our analysis led us to specify the unique beneficial and detrimental properties of governance mechanisms associated to those underlying dimensions. Furthermore, we observed that such benefits and detriments did not remain constant but changed throughout the disruption and adjustment. This observation allowed us to uncover and theorize on governance mechanisms' contingent value and, in turn, their dynamic interplay.

Our overarching contribution is the development of new ways of theorizing about the impact of alliance disruption and subsequent adjustment on the value of alliance governance mechanisms. This core contribution builds on three related contributions. First, our in-depth empirical investigation shows the significance of a revised typology of alliance governance mechanisms and showcases that contractual governance is not necessarily formal and relational governance is not necessarily informal. This contrasts with the traditional approach in the literature to date, which has implicitly equated contractual governance with formal governance and relational governance with informal governance (Zenger et al. 2002, Howard et al. 2019). In particular, informal contractual and formal relational mechanisms have not been the focus of prior research (for exceptions, see, Harmon et al. 2015 and Hoetker and Mellewigt 2009). Second, we analyze and explain the properties and inherent tradeoffs of the various governance mechanisms and how these are altered through disruption and adjustment dynamics. Although existing research has especially focused on legal enforceability and perceived signaling of intentions, we contribute a broader and more nuanced discussion by adding, for instance, the benefits and detriments of codification, which are especially relevant for structuring entrepreneurial $R \& D$ alliances (Reuer et al. 2010). Finally, our analysis allows us to understand how the interplay between different types of governance mechanisms evolves following disruption and adjustment. In doing so, our study provides novel insights into the ongoing debate on the mutual relationship between interfirm governance mechanisms (Poppo and Zenger 2002, Faems et al. 2008, Cao and Lumineau 2015).

\section{Theoretical Background}

Prior research has focused on the different types of alliance governance mechanisms and how they interact, as well as on their evolution, adjustment, and dynamic interplay over time. In the following sections, we first provide an overview of existing research on the nature and interaction of alliance governance mechanisms and eventually propose a revised, more finegrained typology that distinguishes between four 
different mechanisms. We then briefly review the existing research on the dynamics of alliance governance mechanisms. Finally, we emphasize the critical, yet so far sparsely examined, role of alliance disruption, and identify some prevailing blind spots that limit our current theoretical understanding of governing interfirm relationships.

\section{Nature and Interaction of Alliance Governance Mechanisms}

The literature on interorganizational relationships has suggested that two main types of governance mechanisms are at play in alliances: contractual and relational mechanisms. On the one hand, scholars have focused on the role of formal and written contracts as instruments used to organize the intents of collaborating firms into a binding agreement (Reuer and Ariño 2002, 2007; for a review, see Schepker et al. 2014). As legally enforceable promises (Achrol and Gundlach 1999, Lui and Ngo 2004), contractual governance mechanisms explicitly stipulate firms' responsibilities and obligations and specify each party's rights and duties (Ryall and Sampson 2009, Zhou and Poppo 2010). Alliance partners develop contracts to safeguard themselves against their counterpart's self-interested behavior and (mis-)appropriation of value, as well as against risks and future contingencies that may arise (Macneil 1978, Williamson 1985). In turn, management scholars have devoted a great deal of attention to the structure and content of contracts-suggesting that the more contingencies a contract covers, the more complete it is (Mesquita and Brush 2008).

On the other hand, relational governance refers to the extent to which an interfirm alliance is governed by mutually shared social norms (Lusch and Brown 1996, Dyer and Singh 1998) that rule the patterns of behavior to which the parties are expected to conform. Alliance partners will conform to social norms to the extent that the expected behaviors contribute to the relationship's future value (Telser 1980, Poppo et al. 2008). Relational mechanisms rely on selfenforcement (Malhotra and Murnighan 2002, Li et al. 2010). Many studies have shown that trusting and reliable socially embedded relationships can work as an effective governance mechanism to attenuate collaboration risks (Macaulay 1963, Macneil 1980), support coordination, and facilitate information and knowledge exchange across alliance partners (Cannon et al. 2000, Lavie et al. 2012, Zhou and Xu 2012).

Given that partnering firms regularly use a combination of contractual and relational governance mechanisms, many studies have theorized on their mutual relationship and investigated their interaction (Poppo and Zenger 2002, Faems et al. 2008). A debate has ensued to determine whether contractual and relational mechanisms substitute (Das and Teng 1998, Dyer and Singh 1998, Lui and Ngo 2004) or complement (Poppo and Zenger 2002, Liu et al. 2009, Ryall and Sampson 2009, Li et al. 2010) each other (for reviews, see Cao and Lumineau 2015, Poppo and Cheng 2018). The substitution logic implies that the marginal benefits of one mechanism decrease when the benefits of the other mechanism increase, whereas the complementarity approach asserts that the marginal benefits of one type of mechanism increase when the benefits of the other increase (Siggelkow 2002). The most recent studies focus on contingency arguments to suggest that substitution and complementarity are not necessarily incompatible (Handley and Angst 2015). These contingency arguments may include the moderating role of the institutional context and relationship type or the framing and intention of individual contract clauses.

Our review of the existing governance literature leads us to suggest that a reason for these inconsistent findings may stem from the fact that many studies use different conceptual labels for similar governance mechanisms and/or one label for distinct governance mechanisms. In particular, prior research has treated contractual and formal and relational and informal governance mechanisms as somewhat equivalent. For instance, Howard et al. (2019) use the terms "contractual" and "formal" as synonyms. By contrast, Poppo and Zenger (2002) refer to legally binding agreements in writing as "formal contracts," whereas Hoetker and Mellewigt (2009) consider "formal mechanisms" to be written, documented interface structures (e.g., business plans, service level agreements, and performance indices) beyond the actual alliance contract. These apparent discrepancies may be attributable to the fact that two different theoretical approaches and scholarly perspectives actually underlie research on interfirm governance. One line of research focuses its attention on the interplay of legal contracts and relational norms (Ryall and Sampson 2009, Abdi and Aulakh 2017), whereas the othercoming more from sociology and organization theory-emphasizes the use of formal structures and informal patterns as governance mechanisms (Soda and Zaheer 2012, McEvily et al. 2014). As discussed, the prevailing distinction between contractual versus relational mechanisms captures a different dimension of partnership's ruling principles than that captured by the formal versus informal distinction. We thus propose to combine and integrate these two dimensions within a revised typology of alliance governance mechanisms.

On the one hand, the contractual versus relational dimension captures differences in the means to enforce the ruling principles (Lumineau et al. 2020). Although contractual mechanisms are legally enforceable, 
relational ones are self-enforcing. The basic purpose of a contract is to prevent change in the actions of the parties to an agreement or at least to provide compensation for it by having recourse to a third party (Furmston and Tolhurst 2016). In contrast, in a selfenforcing agreement each party decides whether to maintain the agreement or not, and no outside party intervenes to enforce it or to determine violations, assess damages, or impose penalties (Telser 1980). On the other hand, the formal versus informal dimension captures differences in the level of codification of the ruling principles (McEvily et al. 2014). An "agreement may be formal or informal, written or oral" (Ring 2002, p. 146). Formal mechanisms document what the parties have agreed to, while some commitments may be "reached informally with a handshake" (Ring and Van de Ven 1994, p. 98) and not be fully codified.

Although these two dimensions may be implicit in previous studies, by identifying and combining them we propose a typology that offers an organizing framework and distinct definitions of alliance governance mechanisms that may bring clarity to the literature (Table 1): (1) formal contractual governance mechanisms: the set of codified enforceable promises that define the rights and obligations of the parties; for example, termination, auditing, or lawsuit provisions; (2) informal contractual governance mechanisms: the set of uncodified enforceable promises that define the rights and obligations of the parties; for example, confidentiality arrangements, task division, or information exchange; (3) formal relational governance mechanisms: the set of codified patterns of behavior to which parties are expected to conform; for example, exchange of personnel, decision-making rules, or meeting procedures; and (4) informal relational governance mechanisms: the set of uncodified patterns of behavior to which parties are expected to conform, for example, trust and positive interpersonal relationships.

\section{Dynamics of Alliance Governance Mechanisms}

Besides the static analysis of the nature and interaction of alliance governance mechanisms, scholars have devoted attention to their evolution (Mayer and Argyres 2004), adjustment (Reuer and Ariño 2002), and dynamic interplay over time (Faems et al. 2008).

Processual research on interorganizational collaboration (see Majchrzak et al. 2015 for a review) "draws on theorizing that explicitly incorporates temporal progressions of activities as elements of explanation and understanding" (Langley et al. 2013, p. 1). It thus views alliances, including the governance mechanisms used, "dynamically_-in terms of movement, activity, events, change and temporal evolution" (Langley 2007, p. 271). In-depth empirical analyses (Doz 1996, Ariño and de la Torre 1998, de Rond and Bouchikhi 2004, Berends et al. 2011) have shown that interfirm collaborations commonly do not follow "linear sequences of stages" (Berends and Sydow 2020, p. 2) but are "exceedingly unstable" (Majchrzak et al. 2015, p. $1339)$ in the sense that they are continuously in motion, are marked by ever-evolving tensions and contradictions, and require continuous iterations of actions, assessments, and progressive adjustments to changing conditions (Ring and Van de Ven 1994, Koza and Lewin 1998, Das and Teng 2000, Park and Ungson 2001). However, only a handful of studies have explicitly focused on governance mechanisms' evolution, adjustment and dynamic interplay over time (see Table 2 for an overview of the key empirical studies on alliance governance dynamics).

First, previous research has analyzed the evolution of governance mechanisms. Mayer and Argyres (2004) have, for instance, revealed that partnering firms tend to learn over time both how to work together and how to contract with each other. Alliance contracts, which represent the medium and outcome of this learning process, serve as important

Table 1. Revised Typology of Alliance Governance Mechanisms

\begin{tabular}{|c|c|c|}
\hline \multirow{2}{*}{$\begin{array}{l}\text { Level of codification of alliance governance } \\
\text { mechanisms' ruling principles }\end{array}$} & \multicolumn{2}{|c|}{ Means to enforce alliance governance mechanisms' ruling principles } \\
\hline & Contractual & Relational \\
\hline \multirow[t]{2}{*}{ Formal } & Formal contractual governance & Formal relational governance \\
\hline & $\begin{array}{l}\text { Conceptual definition: the set of codified } \\
\text { enforceable promises that define the rights } \\
\text { and obligations of the parties; for example, } \\
\text { termination, auditing, or lawsuit provisions. }\end{array}$ & $\begin{array}{l}\text { Conceptual definition: the set of codified } \\
\text { patterns of behavior to which parties are } \\
\text { expected to conform; for example, exchange } \\
\text { of personnel, decision-making rules, or } \\
\text { meeting procedures. }\end{array}$ \\
\hline \multirow[t]{2}{*}{ Informal } & Informal contractual governance & Informal relational governance \\
\hline & $\begin{array}{l}\text { Conceptual definition: the set of uncodified } \\
\text { enforceable promises that define the rights } \\
\text { and obligations of the parties; for example, } \\
\text { confidentiality arrangements, task division, } \\
\text { or decision making. }\end{array}$ & $\begin{array}{l}\text { Conceptual definition: the set of uncodified } \\
\text { patterns of behavior to which parties are } \\
\text { expected to conform; for example, trust and } \\
\text { positive interpersonal relationships. }\end{array}$ \\
\hline
\end{tabular}


Table 2. Key Empirical Studies on Alliance Governance Dynamics

\begin{tabular}{|c|c|c|c|}
\hline Study & $\begin{array}{l}\text { Mechanisms } \\
\text { studied }\end{array}$ & Dynamics studied & Main findings \\
\hline $\begin{array}{l}\text { Reuer and } \\
\text { Ariño (2002) }\end{array}$ & Contracts & $\begin{array}{l}\text { Postformation (re) } \\
\text { adjustments }\end{array}$ & $\begin{array}{l}\text { Partnering firms tend to renegotiate the alliance contract when they } \\
\text { experience a misalignment between the chosen governance structure } \\
\text { and transaction features. Contractual alterations are also more likely } \\
\text { when partners have made significant transaction-specific investments, } \\
\text { when firms initially employed less extensive contractual safeguards, } \\
\text { and when environmental or strategic changes affect the alliance. }\end{array}$ \\
\hline Reuer et al. (2002) & $\begin{array}{l}\text { Contracts, } \\
\text { joint } \\
\text { boards and } \\
\text { monitoring } \\
\text { mechanisms }\end{array}$ & $\begin{array}{l}\text { Postformation (re) } \\
\text { adjustments }\end{array}$ & $\begin{array}{l}\text { Postformation governance changes (i.e., contract alterations, board } \\
\text { changes, and adjustments of monitoring mechanisms) are influenced } \\
\text { by both alliance characteristics and parent firms' previous technology- } \\
\text { specific and partner-specific alliance experience. Alliances with a } \\
\text { broader scope, a lower division of labor, and a high strategic relevance } \\
\text { are more likely to experience ex post governance changes. }\end{array}$ \\
\hline $\begin{array}{l}\text { Mayer and } \\
\text { Argyres (2004) }\end{array}$ & $\begin{array}{l}\text { Contracts and } \\
\text { trust }\end{array}$ & $\begin{array}{l}\text { Learning and (co) } \\
\text { evolution }\end{array}$ & $\begin{array}{l}\text { By engaging in multiple joint projects over time, partners learn both how } \\
\text { to work together and how to contract with each other. Contracts, which } \\
\text { represent both the medium and outcome of this learning process, serve } \\
\text { as repositories for knowledge and thus tend to become more detailed } \\
\text { over time. In addition, joint learning and negotiating and drafting } \\
\text { increasingly detailed contracts facilitate the development of trust by } \\
\text { clarifying each party's roles and responsibilities over time. }\end{array}$ \\
\hline $\begin{array}{l}\text { Klein Woolthuis } \\
\text { et al. (2005) }\end{array}$ & $\begin{array}{l}\text { Contracts and } \\
\text { trust }\end{array}$ & $\begin{array}{l}\text { (Co) evolutionary } \\
\text { interplay }\end{array}$ & $\begin{array}{l}\text { Contracts and trust can be both substitutes and complements, depending } \\
\text { on the main function, the content, and the intentions with which a } \\
\text { contract is drawn up and used. }\end{array}$ \\
\hline Faems et al. (2008) & $\begin{array}{l}\text { Contracts and } \\
\text { trust }\end{array}$ & $\begin{array}{l}\text { (Co) evolutionary } \\
\text { interplay }\end{array}$ & $\begin{array}{l}\text { Contractual and relational mechanisms mutually influence each other, } \\
\text { both within and between alliance transactions. Contracts with a similar } \\
\text { degree of contractual formalization can trigger positive and negative } \\
\text { reinforcing trust dynamics at both operational and managerial levels, } \\
\text { depending on the nature of the contractual formalization (broad } \\
\text { versus narrow) and on how the contract is actually applied (flexible } \\
\text { versus rigid). }\end{array}$ \\
\hline $\begin{array}{l}\text { Gulati and } \\
\text { Sytch (2008) }\end{array}$ & Trust & Evolution & $\begin{array}{l}\text { The longer the history of interaction between organizations and } \\
\text { organizational boundary spanners, the higher the level of } \\
\text { interorganizational trust. Joint history does not, however, linearly } \\
\text { translate into trust because exchange partners first need to go through a } \\
\text { certain period of ambivalence at the beginning of their relationship. }\end{array}$ \\
\hline Huber et al. (2013) & $\begin{array}{l}\text { Contracts and } \\
\text { trust }\end{array}$ & $\begin{array}{l}\text { (Co) evolutionary } \\
\text { interplay }\end{array}$ & $\begin{array}{l}\text { Although prior research has considered contractual and relational } \\
\text { mechanisms as either substituting or complementing each other at all } \\
\text { points in time, they can, in fact, be both substitutes and complements } \\
\text { for each other at different points in time. Contextual events, such as } \\
\text { goal misalignment, can dynamically shift the relationship between } \\
\text { governance mechanisms from substitution to complementarity and } \\
\text { vice versa. }\end{array}$ \\
\hline $\begin{array}{l}\text { Oliveira and } \\
\quad \text { Lumineau (2017) }\end{array}$ & $\begin{array}{l}\text { Contracts and } \\
\text { project } \\
\text { integrators }\end{array}$ & $\begin{array}{l}\text { (Co) evolutionary } \\
\text { interplay }\end{array}$ & $\begin{array}{l}\text { Just as coordination needs tend to change throughout the life cycle of a } \\
\text { collaborative project, so the relative importance and interplay of } \\
\text { governance mechanisms differ in various project phases. Alliance } \\
\text { managers must therefore develop a trajectory awareness about the } \\
\text { appropriate timing and matching of different governance mechanisms } \\
\text { with the prevalent coordination needs. }\end{array}$ \\
\hline Howard et al. (2019) & $\begin{array}{l}\text { Formal/ } \\
\text { contractual } \\
\text { and } \\
\text { informal/ } \\
\text { relational } \\
\text { mechanisms }\end{array}$ & $\begin{array}{l}\text { (Co) evolutionary } \\
\text { interplay }\end{array}$ & $\begin{array}{l}\text { Formal and informal governance mechanisms, which are } \\
\text { semicoupled-as their movement is not directly connected to the } \\
\text { movement of the other-can become functional or dysfunctional over } \\
\text { time. They also can be convergent or divergent, as what is functional } \\
\text { for one side of the dyad can be dysfunctional for the other. It is the } \\
\text { management of governance mechanisms' functions and dysfunctions } \\
\text { over time, rather than their nature as substitutes or complements, that } \\
\text { drives an alliance's exchange performance. }\end{array}$ \\
\hline $\begin{array}{l}\text { Brattström and } \\
\text { Faems (2020) }\end{array}$ & Trust & Evolution & $\begin{array}{l}\text { Collaborating firms do not necessarily have to act as monolithic entities } \\
\text { as there could be multiple coalitions with different beliefs and } \\
\text { competing partnership logics within one of or even within both of the } \\
\text { partnering organizations. Divergent intraorganizational logics tend to } \\
\text { impair the (self-) reinforcing formation process and reliable use of } \\
\text { interorganizational trust by preventing norms of reciprocity from } \\
\text { being established. }\end{array}$ \\
\hline
\end{tabular}


repositories for knowledge and thus tend to become increasingly detailed over time. Likewise, Gulati and Sytch (2008) have shown that interorganizational trust is essentially a time-based phenomenon (see also Schilke and Cook 2013) that develops through the collective accumulation of experience and spans the partnering organizations, but especially specific groups of people (Brattström and Faems 2020).

Second, research has explored postformation adjustments of alliance governance. Here, Reuer and Ariño (2002) have shown that partnering firms tend to renegotiate their alliance contract when they experience a misalignment between the chosen governance structure and transaction features (see also Reuer et al. 2002). Similarly, as social bonds tend to be fragile and expectations can be easily violated, scholars have discussed how trust can be adjusted and repaired (for an overview, see Kramer and Lewicki 2010).

Last, research has examined the dynamic interplay of multiple governance mechanisms over time. For instance, Klein Woolthuis et al. (2005) noticed that contractual and relational governance can be both substitutes and complements depending on the specific intentions (e.g., as a legal safeguard versus a sign of commitment) with which the alliance contracts are designed and used. Similarly, Faems et al. (2008) observed that the nature of contractual mechanisms can trigger different kinds of trust dynamics at both operational and managerial levels and that contract application and trust dynamics are inherently linked and coevolve over time. More recently, scholars have argued that contractual and relational mechanisms can actually be both substitutes and complements at different points in time. Huber et al. (2013), for instance, suggested that the relationship between contractual and relational governance oscillates between substitution and complementarity and that contextual events, such as goal misalignment spur those oscillations; meanwhile, Oliveira and Lumineau (2017) showed, in the context of interorganizational project networks, when and how the interplay of different governance mechanisms changes throughout the different relationship phases of the project lifecycle (see also Howard et al. 2019).

Overall, the existing research has shown that alliance governance mechanisms-albeit designed and used to structure and thus stabilize collaborationsare not (individually nor jointly) static, nor do they follow a universal developmental trajectory; instead, they are dynamic and subject to diverse changes over time.

\section{Alliance Disruption}

Despite this line of research, which analyzes partnership dynamics in general and the dynamics of alliance governance mechanisms in particular, the literature has yet to pay much attention to the critical influence of disruption on alliance governance mechanisms. At the same time, an emerging stream of studies has begun to point out the importance of gaining a better theoretical understanding of disruption and its consequences in interorganizational relationships (Bakker 2016, Bruyaka et al. 2018, Schmitz et al. 2020). Disruption, which can be defined as the aftermath of a nonroutine event that significantly impairs the normal course of a partnership and makes it difficult for the partners to continue their collaboration in the normal way, is in fact commonplace in alliances (Lui and Ngo 2005, Kale and Singh 2009). Despite its frequency, disruption often involves a number of potential negative effects, ranging from a loss of knowledge, a reduction in interpersonal trust, and increased uncertainty (Bendapudi and Leone 2002, Palmatier 2008). Such severe changes bring with them uncertainty in the context that surrounds the alliance, making it "costly, perhaps impossible to describe the complete decision tree" (Williamson 1975 , p. 23) and making adaptation particularly difficult. Disruption, which represents a special type of ex post contingency that impacts the operation and evolution of an alliance (Reuer and Ariño 2002), can take different forms, including pandemic crises (Arslan and Tarakci 2020), technological and regulatory shifts (Madhavan et al. 1998), changes in alliance partner ownership (Bakker 2016), the sudden loss of key personnel (Schmitz et al. 2020), delivery problems (Wang et al. 2014), and severe misunderstandings and disputes (Lumineau and Malhotra 2011). Our detailed analysis of the literature, summarized in Table 3, suggests three main forms of disruption in interorganizational relationships, depending on the locus of the triggering event ${ }^{1}$ : (1) disruption triggered by external events that happen beyond the partnering organizations, (2) disruption triggered by partner-specific events that happen within the partnering organization but (initially) outside the immediate scope of the partnership, and (3) disruption triggered by relationship-specific events that happen within the immediate scope of the partnership.

Our study stands at the convergence of three important blind spots in the existing research on alliance governance mechanisms: (1) the conceptualization of focal constructs, (2) the analysis of these constructs' dynamics, and (3) the impact of disruption on the value of alliance governance mechanisms. In turn, building on our fine-grained typology of governance mechanisms, we study how governance mechanisms are beneficial or detrimental to an alliance over time when it undergoes disruption and subsequent adjustment. Despite its prominence in many alliances, we have an insufficient understanding of how these 
Table 3. Overview and Categorization of Key Empirical Studies on Disruption in Interorganizational Relationships

\begin{tabular}{llll}
\hline Study & Partnership studied & Main disruption trigger studied & Conceptual definition of disruption \\
\hline (1) Disruption triggered by external events that happen beyond the partnering organizations & \\
Madhavan et al. (1998) & Network & Technological and regulatory shocks & None \\
Arslan and Tarakci (2020) & Alliance & Pandemic & None \\
\hline
\end{tabular}

(2) Disruption triggered by partner-specific events that happen within the partnering organizations

(a) Events related to the partner's strategy

Bakker (2016) Alliance Alimadadi etal. (2019) $\begin{gathered}\text { Buyer-supplier } \\ \text { relationship }\end{gathered}$

(b) Events related to the partner's organization de Rond and
Bouchikhi (2004)

Schmitz et al. (2020)

Alliance

Buyer-supplier relationship

This study

Alliance

Acquisition (ownership change) of one partner and a revised partnership strategy

Firm entry in and exit from a multiparty alliance

Change of key personnel at the alliance
interface
Change of key salespeople in a customer
relationship

Internal restructuring
"In an alliance that is reconfigured after formation (...) routines are likely to be upset-disrupting established patterns of interaction and coordination mechanisms." (p. 1920)

"Discontinuities in structures, contexts, routines, expectations and perceptual frameworks (...) can cause disruption and problems of understanding in interorganizational relationships." (p. 3)

None

"A relationship disruption refers to a change of salesperson in the relationship with the customer." (p. 66)

"Aftermath of a nonroutine event that significantly impairs the normal course of a partnership and makes it difficult for the partners to continue their collaboration in the normal way."

(3) Disruption triggered by relationship-specific events that happen within the immediate scope of the partnership

Bode et al. (2011) Buyer-supplier

Supplier quality problems, delivery failures, "[D]isruptions triggered in the network of relationship and plant fires

suppliers (...), that significantly threatened or impaired the normal course of business operations of the focal firm." (p. 833)

Zhang et al. (2018) Buyer-supplier

Disputes about quality, delivery, after-sales "Exchange disruptions may result from support, or technology sharing partner opportunism (...), [or] misunderstandings between exchange partners." (p. 216)

dynamics impact interfirm governance mechanisms. Thus, in this study, we are interested in building and extending theory on alliance governance mechanisms by examining: how does the value of different governance mechanisms change when an alliance undergoes disruption and subsequent adjustment?

\section{Methods and Data \\ Research Design and Setting}

The study is based on an in-depth examination of the governance mechanisms in place in the PharmaCoBeta alliance (the names of both companies have been changed for reasons of confidentiality), a strategic alliance in the field of veterinary drugs, a subfield of the pharmaceutical industry. ${ }^{2}$ We longitudinally studied a single (Siggelkow 2007, Ozcan et al. 2017) yet embedded case (Yin 2014), with units of analysis at two levels: the various governance mechanisms used throughout different periods of the relationship at the lower level; and the performance and evolution of the alliance itself at the higher level. Qualitative case studies are particularly suited to examine microlevel and dynamic phenomena and to "explain the relationship between events in a process" (Pentland 1999, p. 711). They thus facilitate building and extending theory (Eisenhardt 1989) about "how and why things emerge, develop, grow, or terminate over time" (Langley et al. 2013, p. 1). Given our interest in gaining an in-depth understanding of finegrained dynamics of alliance governance mechanisms, a single, longitudinal case study is appropriate (Siggelkow 2007, Ozcan et al. 2017). Table 4 outlines the methodological strategies that we applied to ensure the scientific rigor of our research design (Gibbert et al. 2008).

PharmaCo is one of the world's leading pharmaceutical corporations, headquartered in Europe. The multinational firm employs more than 100,000 people worldwide and has a regular annual turnover of more than US\$30 billion. Within its human and animal 
Table 4. Methodological Strategies Followed for Ensuring Scientific Rigor of Research Design

\begin{tabular}{lc}
\hline Validity tests & Suggested strategies and rationale \\
\hline $\begin{array}{c}\text { Construct validity: Applying } \\
\text { correct operational measures } \\
\text { for the concepts being studied. }\end{array}$ & $\begin{array}{c}\text { Use multiple sources of evidence. This allows } \\
\text { triangulation and the development of } \\
\text { converging lines of inquiry. }\end{array}$
\end{tabular}

Internal validity: Establishing a causal relationship, whereby certain conditions are shown to lead to other conditions, as distinguished from merely spurious relationships.
Establish a verifiable chain of evidence. This allows others to follow the derivation of evidence from the initial research question to the ultimately explanatory insights and developed theorizing.

Let informants review draft case study reports. This corroborates the essential facts and evidence presented in the case report, reducing the likelihood of false reporting or misinterpretation of events.

Have a general analytic framework. Relying on a theoretical orientation helps the researcher approach the analysis and choose from among different analytical techniques.

Have a dominant analytical procedure. This allows to systematically organize the data and ensures the correctness of inferences drawn from the case evidence, thus ruling out alternative explanations.
External validity: Establishing the Use replication logic in multiple case studies. general domain to which the study's findings can be generalized, keeping in mind that the aim is to generalize to theory and not the population.

Reliability: Demonstrating that the operations of a study can be repeated, with the same results.
This allows researchers to establish the conditions under which a phenomenon is likely to be found and those where it is unlikely to be found.

Setup of a case study database. This allows other researchers to retrieve the evidence directly.
Implementation

We used the following sources of evidence: (1) Semistructured interviews with all major representatives involved in the alliance on both sides. (2) Publicly available documents, such as press releases, annual reports and industry studies. (3) Initial and amended contractual documents of the alliance. (4) Other private documents, including project progress reviews, due diligence reports and meeting minutes.

The case description contains a large amount of raw data from the case database (e.g., interview quotes and excerpts from archival documents).

Four of our informants reviewed the case report. They clarified certain aspects and gave additional information on circumstances highlighted in the case report.

We analyzed the case through a governance lens. This theoretical focus guided the representation and analysis of the case evidence.

We applied a combination of a narrative strategy, temporal bracketing, and explanation building. We first built a comprehensive chronologically structured narrative. In a second step, we used a temporal bracketing approach to identify distinct periods. Finally, we linked the effect of certain governance configurations during each period to the respective alliance outcomes, aiming to explain and theorize the governance dynamics over time.

Given the fact that we studied a revelatory, single case, the traditional replication logic does not apply. However, we linked our insights to other documented cases of alliance governance dynamics.

Our case database includes all the labeled audio files and written interview transcripts, as well as the entire collection of public and private documents, organized chronologically.

Note. The structure of the table is adapted from Ariño and Ring (2010, p. 1079-1080), who followed suggestions provided by Gibbert et al. (2008) and Yin (2014).

health business, PharmaCo focuses on organic growth and acquisitions, as well as joint research and collaborative in-licensing of medical compounds from external partners. Beta, on the other hand, is a small, yet growing, entrepreneurial biotech firm based in the United States. Founded by a group of former employees of another major pharmaceutical company, the firm currently employs about 20 individuals. Beta's activity mainly focuses on exploring and developing innovative drug delivery systems for active pharmaceutical compounds. The key objective of the alliance was to develop, produce, and market various new veterinary products based on Beta's unique drug delivery technology. The parties were complementary in the sense that Beta provided its specialized scientific know-how, whereas PharmaCo was supposed to finance and support product development and the registration process and contribute its wellknown corporate trademark. The alliance was envisaged to be centered mainly on downstream activities, such as product formulation, testing, registration, and commercialization-thereby pooling and leveraging the partners' already existing capabilities. We discuss in detail in the conclusions section how the specific 
features of the case may represent boundary conditions (Busse et al. 2017).

The PharmaCo-Beta alliance represents an archetypal setting, which exhibits many characteristics and common obstacles that frequently occur in the process of establishing, structuring, and managing interfirm alliances. Given that R\&D collaborations between major pharmaceutical companies and entrepreneurial biotech firms are ubiquitous and continue to increase yearly, the industry has presented a highly popular setting for alliance research (Reuer et al. 2002, Zollo et al. 2002). Dedicating a large part of their R\&D budget to interorganizational projects, incumbent firms rely extensively on external partnerships to gain access to innovative agents and technologies. Still, these partnerships are risky, given the intensity and strategic importance of R\&D investments (Henderson and Cockburn 1994), the uncertainty and high failure rate of drug development, and the fact that collaborations in this industry expose the participating parties to the risk of unintended knowledge spillover (Laursen et al. 2017).

We chose the PharmaCo-Beta alliance according to the rationale of theoretical sampling (Eisenhardt 1989). First and foremost, we purposefully selected and gained access to this alliance because it had gone through what seemed to be interesting changes in governance mechanisms. After a promising start, the PharmaCo-Beta alliance was subject to a marked disturbance triggered by an internal restructuring at PharmaCo. This led to increasingly severe relationship strains and ultimately to an adjustment initiated by PharmaCo's corporate Alliance Management Group. Thus, the PharmaCo-Beta alliance seemed to be particularly suitable for adopting a processual lens and studying alliance governance dynamics longitudinally (Langley et al. 2013). As the research unfolded, disruption and the subsequent adjustment surfaced as prominent dynamics. Van Maanen (1979) pointed out that "the selection of substantive topics in a given study cannot be disembodied from the actual research process itself" (p. 524), a concept that resonated with us throughout our research journey. Starting with a general interest in alliance governance dynamics, the research process led us to focus on how the value of alliance governance mechanisms changes as a consequence of disruption and subsequent adjustment dynamics; this quickly became the substantive topic of our study. In the case of the PharmaCo-Beta alliance, disruption took the form of a process of internal restructuring within one of the partnering organizations-involving a substantial change of key personnel at the alliance interface (de Rond and Bouchikhi 2004, Schmitz et al. 2020). We thus specifically examined disruption caused by an alliance partner-specific event that originally "occur [ed] outside the scope of the alliance" but "nevertheless trigger[ed] internal tensions between the partners" (Bruyaka et al. 2018, p. 449). Second, we had a promising opportunity for uncommon research access to a phenomenon that may not be readily observable to outsiders-another condition that makes the single-case research design appropriate (Ozcan et al. 2017). We had access to all the contractual documents of the alliance. These types of documents are often hard to obtain because they are usually subject to strict confidentiality (Ring 2002). Third, we were able to access both sides of the alliance, which enabled us to analyze the relationship's unfolding dynamics from both points of view. Moreover, we had the possibility to interview almost all the individuals directly involved in the alliance, including the senior management of both firms. By gaining access to both firms and various knowledgeable informants from different hierarchical levels and diverse functional areas, we went beyond many existing alliance governance studies (Reuer and Ariño 2007), which are one-sided, based on statements of one key informant, and thus conceive collaborating firms as homogeneous actors.

\section{Data Collection and Analysis}

In order to gain an in-depth understanding of the collaborative dynamics, we interviewed key participants involved in the alliance from both organizations. ${ }^{3}$ We conducted interviews with informants from different hierarchical levels (e.g., frontline, dayto-day scientists, and senior executives) and from multiple functional areas, such as marketing, $R \& D$, and regulatory affairs. In total, we conducted 24 interviews with 15 informants (see Table 5 for an overview of collected data). ${ }^{4}$ The interviews ranged from half an hour to two hours, with an average duration of 51 minutes. All interviews were recorded on tape and verbatim transcribed. Interviews and transcripts were labeled, categorized along keywords, and integrated into a comprehensive case study database (Yin 2014).

The interviews were semistructured and organized around the chronology of the major events in the alliance. As we were particularly interested in the dynamics of the different governance mechanisms used within the alliance, we asked the informants to reflect on the initial governance setup and to elaborate on subsequent changes and adjustment processes as well as their triggering events. Specifically, we asked them to report on the rationale behind the choice of specific mechanisms, their experienced (dys)functions, and changes applied to them; we also asked them to reflect on the influence of governance configurations on the operation and the targeted and achieved outcomes of the alliance at various points in 
Table 5. Overview of Collected Data

Data type Description of data (number of interviews/number of pages)

Interviews

PharmaCo: 14 interviews (average: 53 minutes)

Beta: 10 interviews (average: 49 minutes)

Contractual documents

Other private documents

Public documents
Head of Animal Health North America: 2

Head of Development Animal Health North America: 2

Head of Technical Development Animal Health North America: 2

Head of Global Development Animal Health: 2

On-Site Project Manager: 2

Head of Marketing Animal Health North America: 1

Head of Business Development Animal Health: 1

Regulatory Affairs Manager: 1

Responsible Alliance Manager: 1

Chief Executive Officer and Founder: 2

Chief Financial Officer and Chief Operating Officer: 2

Chief Scientific Officer: 2

Vice President of Business Development and Marketing: 2

Vice President of R\&D and Regulatory Affairs: 1

Technical Director: 1

Assignment and license agreement

Relationship agreement

Minor amendment to the assignment and license agreement

Amended assignment and license agreement

Amended and restated relationship agreement

Project progress reviews, due diligence reports, and meeting minutes

Press releases, newspaper articles, annual reports, industry studies
55 pages

28 pages

3 pages

170 pages

33 pages

57 pages

527 pages time. In addition, we gained information about the informants' role and their personal experience within the partnership, their interaction with members of the partner firm, as well as the temporal evolution of their involvement and commitment toward the partnership.

We also obtained access to both private and public archival data. Most notably, we had access to the various versions of the alliance contract and related documents used to set up the relationship, comprising about 280 pages in total. Other private documents included project progress reviews, due diligence reports, and meeting minutes. Publicly available materials included press releases, newspaper articles, annual reports, and industry studies. Table 5 provides an overview of the nature and length of the archival data examined. We made extensive use of these data to prepare the interviews and to challenge informants' memories and cross-check their perceptions with the collaboration's documented trail.

Interviews were carried out in two waves between September 2014 and November 2017. We started our data collection in 2014, about four years after the initial setup of the alliance (2010), three years after an internal restructuring at PharmaCo had triggered alliance disruption (2011), and about one year after the adjustment of the alliance initiated by PharmaCo's corporate Alliance Management Group (2013). The second wave of interviews was focused on specific queries and aimed at clarifying outstanding issues. Our interview data were thus, for the most, part collected retrospectively. ${ }^{5}$ In order to mitigate potential cognitive biases that may occur when using interview data to reconstruct historical events (Eisenhardt and Graebner 2007), we took the following measures (see also Table 4 for a general overview of the methodological strategies followed for ensuring scientific rigor of research design). First, we triangulated our data, using different types of evidence: interviews and public and internal archival documents (Eisenhardt 1989). Second, we deliberately asked informants to reflect on specific events and issues, rather than abstract theoretical constructs or past beliefs, in order to reduce problems created by respondents' selective retrospective bias and impression management (Golden 1992). Third, we aimed to control for potential informant biases by interviewing multiple informants. Asking similar questions to different people in the two firms allowed us to verify individual reports and develop a comprehensive picture by getting complementary viewpoints on the same set of events. Fourth, by guaranteeing anonymity and confidentiality throughout the entire study, we were able to reduce the likelihood of a social desirability bias. Last, we repeatedly circulated drafts of our case description and analysis among key informants in order to correct inaccuracies and factual 
errors, to fine-tune the case reconstruction, and to cross-check our interpretations and the derived explanatory insights.

Following suggestions for qualitative data analysis (Miles and Huberman 1984, Yin 2014) about how to move from description to explanation (Pentland 1999) and lift raw data to a conceptual level, we took two main steps in our theory development and extension effort. First, we followed a narrative organizing scheme as a way of descriptively representing the case data in a systematic organized form (Langley 1999). In this way, we gained an overview of the alliance and how it evolved over time. We focused on understanding the rationale of the collaboration, the partners' individual as well as joint goals and expectations, the unfolding of alliance activities and the nature of the problems that progressively surfaced. Thus, we initially mapped the case happenings chronologically - thereby creating a rich historical descriptive narrative of the case. Second, we went beyond the surface description and moved to a more abstract level, focusing directly on the governance concerns and consequences, the triggering events and causes, and the resulting (re)actions of and interactions between the partners. To this end, we used a temporal bracketing strategy (Langley 1999) to identify key periods in the evolution of the alliance. We decomposed and organized the case narrative into three successive periods around the two major critical dynamics in the partnership ${ }^{6}$; the alliance disruption dynamic triggered by an internal restructuring at PharmaCo (shift from period 1 to 2), followed by an alliance adjustment dynamic triggered by a managerial intervention of PharmaCo's corporate Alliance Management Group (shift from period 2 to 3). Based on these temporal brackets and having reconstructed the governance mechanisms at the outset of the alliance, we extracted evidence on both the nature and interplay of governance mechanisms in the wake of the two dynamics identified. Specifically, we analyzed how the value of governance mechanisms - in terms of their relative benefits and drawbacks - was affected by the dynamics of the disruption and adjustment. ${ }^{7}$ At this stage, we also integrated insights from an in-depth content analysis of the different versions of the formal alliance contract. This provided valuable information on the extent and precise nature of contractual formalization. Specifically, we looked at the content and the precision with which the clauses were laid down-in contrast to considering only the number of pages, the quantity and/or types of clauses. This allowed us to comprehend the contract's main functions and uncover the intentions with which the alliance contract was written and used by the partners (Klein Woolthuis et al. 2005, Faems et al. 2008). Finally, we were not only interested in the nature of the dynamics and the relationship between different governance mechanisms but also in their varying value and joint impact on the alliance's operation and outcomes over time. We therefore assessed the partnership's performance and other alliance outcomes, such as "the technological success [...], the degree to which the project remained within budget and time schedule, and [...] the degree to which partners were able to solve problems within the relationship" (Klein Woolthuis et al. 2005, p. 821). For this purpose, we used both interviews and internal archival documents, such as project progress reviews.

By studying the case primarily through a governance lens, our efforts in empirical analysis and theory development and extension were guided by the concepts and theoretical insights discussed in prior governance literature. As we strived to gain a processual, rather than a variance-oriented, understanding and to develop theorizing that "explicitly incorporates temporal progressions of activities as elements of explanation" (Langley et al. 2013, p. 1), we focused in particular on how the two main dynamics of disruption and adjustment impacted the value of the governance mechanisms used in the alliance.

In the following presentation of our findings, we distinguish between a descriptive perspective and an abstract, theoretically informed perspective on the case events. In doing so, we successively describe the major events and activities and their impact on the alliance, making extensive use of excerpts from both interviews and archival data; each description is followed by a more analytical section that highlights the particular governance concerns and consequences and provides a theoretically informed interpretation of the critical incidents.

\section{Governance Dynamics at the PharmaCo-Beta Alliance}

In 2009, PharmaCo's Animal Health Division became interested in Beta. At the time, Beta had a pioneering advanced drug delivery system (ADDS), for which the firm sought funding and market access opportunities. The ADDS was a universally applicable, softchew formulation for veterinary drugs that was free of animal protein but still highly palatable. The system was likely to act as an innovative platform for numerous veterinary drugs. The planned long-term collaboration aimed to combine Beta's special expertise in ADDS R\&D with PharmaCo's far-reaching experience in registration, manufacturing, and marketing. New pharmaceutical products based on Beta's ADDS promised to provide PharmaCo with a unique selling point, and thus a potential competitive advantage in the increasingly competitive animal health 
market. The high potential and strategic significance of Beta's ADDS provided PharmaCo with a powerful incentive not to use the bargaining power stemming from its bigger size to the detriment of Beta.

\section{The Outset: Alliance Formation}

After several months of exploratory meetings, as well as financial and technical due diligence, official contract negotiations began in mid-2010. They were carried out by Beta's founding and leadership team, and PharmaCo's North American Animal Health Business Development and Licensing Group. In October 2010, the PharmaCo-Beta agreement was formally signed. The alliance was rooted in the common idea that Beta should largely independently develop and register various new veterinary products by combining both generic and PharmaCo-owned active ingredients with Beta's innovative ADDS. Thus, Beta would be in charge of the advanced development of new products in various pharmaceutical areas (e.g., parasitology, anti-infectives, analgesics, and geriatrics), whereas PharmaCo would finance the development and registration and handle the subsequent downstream commercialization of the new products. The two companies envisioned obtaining their first joint products within one to two years.

During the negotiations, both parties mutually agreed that Beta would be given considerable leeway and autonomy to develop the envisioned products up to the point of regulatory submission. Beta aimed to preserve its entrepreneurial freedom and sought to control the development process, whereas PharmaCo's Business Development Group feared that a heavyhanded involvement by PharmaCo-a big and rather bureaucratic, procedure-driven multinational-might stifle Beta's speed and innovativeness. Both sides confirmed that the initial alliance setup intentionally rested on strict task division, minor information exchange, and only limited monitoring activities:

PharmaCo wanted to tap into the speed and agility, and the entrepreneurial spirit of Beta. The way the contract was set up allowed Beta to do that without a lot of involvement from PharmaCo. In the original contract that was the intent. [...] We wanted to move faster. Therefore, we said, let us make sure to design a contract that ensures that for Beta. (PharmaCo's Head of Animal Health North America)

We were very comfortable with the contract. We felt it gave us the responsibility and the authority over the registration process. [...] We did not want to get tangled up with their R\&D Group getting too much involved with the development and the regulatory process. We were comfortable that we had responsibility and authority and control to do that. (Beta's Chief Scientific Officer)
The financial structure of the partnership consequently incentivized fast product development and timely submissions to the U.S. Food and Drug Administration (FDA). It centered on a payout plan that linked PharmaCo's payments to Beta to certain milestone achievements (such as prototype formulation, palatability confirmation, stability approval, and agency submission) within different product profiles.

The Payments shall be made with respect to particular R\&D Stages on a product by product basis, [...], with a particular R\&D Milestone Payment being due and payable to Beta as provided in Annex 5 within sixty (60) days (i) after PharmaCo receipt of written certification by Beta of the successful achievement of such R\&D Stage, [...]. Beta and PharmaCo shall in good faith agree on the criteria to be met in order to be in the position to decide whether a particular R\&D Stage has successfully been achieved. It is anticipated that through close collaboration of Beta and PharmaCo [...], the criteria for completion of all R\&D Milestones will be fixed prior to completion of each R\&D stage. (Excerpt from the assignment and license agreement)

Given the uncertainty regarding the exact development procedure and the common objective of getting the alliance operations up and running as soon as possible, the partners refrained from spending too much time and effort on specifying and formally documenting every detail. As such, they deliberately did not incorporate into the alliance contract detailed process descriptions, elaborated product profiles, and clauses specifying exactly how Beta had to achieve the milestones. A Beta representative accordingly stated that in the initial contract "the nature of the details was entrusted to us" (Beta's Vice President of Business Development and Marketing). He further expounded:

The first contract was deliberately set up to have a large degree of trust within it. [...] We at Beta favored the trust. And this team that we worked with at PharmaCo, this business development team, also favored that approach. [...] It was a business development relationship, and we were kept away from the R\&D team, and that was acknowledged by PharmaCo as an important element. (Beta's Vice President of Business Development \& Marketing)

In order to ensure a sufficient level of coordination and information exchange, the parties agreed on and formally recorded the implementation of a defined committee structure. A strategic relationship committee was responsible for "endorsing achievement of the R\&D milestones and timelines [...] and to confirm the completion of particular R\&D stages, completed submission and other regulatory filings" (excerpt from the relationship agreement). An operating committee, which was supposed to meet quarterly, would handle the day-to-day issues. 
During the first five months, the alliance essentially operated and performed as foreseen. Beta threw itself into developing different targeted products, implementing their entrepreneurial R\&D approach. In line with the jointly developed spirit, the collaboration was characterized by high autonomy and limited interaction between the parties. Beta's Technical Director reported:

We felt we had the permission to move ahead as we wished. There were quarterly meetings and basically in these meetings we presented updates. [...] However, PharmaCo's technical team was not involved. It was as if we had permission to continue on as we wished.

Although making rapid progress, the parties failed to fully implement some of the coordination structures as initially envisaged. For example, as the relationship started to gain traction, the firms neglected to draw up detailed, formally established product profiles that would specify and document the concrete nature and the development plan of the different products. In addition, PharmaCo's project manager was stationed in Europe because of tax considerations. Nonetheless, Beta's Chief Executive Officer noted that "there was mutual trust between us and PharmaCo. [...] I felt very comfortable with the people, with PharmaCo, and I thought they were very trustworthy."

The by and large well-functioning alliance setup was, however, markedly disturbed by an internal restructuring within PharmaCo's veterinary drug division. Over the course of this internal change, the PharmaCo-Beta Alliance was transferred from the PharmaCo's business development group to its R\&D department. The relocation constituted a significant turning point in the relationship.

\section{Analytical Interpretations of Alliance Formation}

Before we further describe and specify the impact of this disruptive event on the alliance and its governance mechanisms, it seems opportune to analyze the collaboration's initial governance setup. Overall, the design of the governance mechanisms was shaped by the common idea of tapping into an entrepreneurial development approach, a collaborative spirit focused on joint value creation, and the mutually shared concern that an intensive interference by PharmaCo would be detrimental to the alliance. To achieve the envisioned targets and to mitigate risks, the parties formally set up a fairly simple alliance contract. The formal contract mainly focused on legally enforceable clauses related to, in particular, safeguarding the parties' interests, intellectual property, patent and control rights, and spillover (such as pledge of secrecy and limitations on the freedom to work with others).

However, many other less standardized, more partner- and relationship-specific issues-for example, the level of oversight, decision-making powers, project plans, the exact roles and responsibilities, or the clear division of tasks and time paths-were not formally documented and incorporated into the official written agreement. Not captured through formal contractual mechanisms, some aspects were, instead, agreed on informally (Montesquieu 1989, Harmon et al. 2015). For instance, the fact that Beta had control over the development process and did not need to coordinate with PharmaCo's R\&D group was sealed with a handshake. In addition, the relationship was envisioned to be governed through relational mechanisms. On the one hand, the negotiation process between Beta representatives and PharmaCo's business development group had generated mutual trust and confidence that the other party would behave as expected in order to comply with their assumed obligations. On the other hand, several formally agreed mechanisms, such as defined committee and reporting structures (Hoetker and Mellewigt 2009), were established and agreed in a relationship agreement in order to facilitate coordination and the development of social, informal linkages. Thus, the analysis of the setup of the PharmaCo-Beta alliance provides indications that the prevalent distinction between contractual versus relational mechanisms proves too broad. Instead, our empirical observation showcases the coexistence of four different governance mechanisms and thus supports the revised governance typology (Table 1) that combines two dimensions: contractual versus relational and formal versus informal. In the following section, we use this revised, more fine-grained typology of alliance governance mechanisms as a conceptual framework and theoretical guidepost for the further analysis of the governance dynamics of the PharmaCo-Beta alliance.

\section{Dynamic 1: Alliance Disruption Triggered by Internal Restructuring}

Although the initial alliance setup seemed quite functional at the outset, the situation changed markedly in spring 2011. About six months after the official launch of the alliance, Beta's reporting line changed from PharmaCo's business development groupwhich had initiated and championed the partnershipto PharmaCo's in-house R\&D group. The structural relocation, which also involved personnel changes at various levels, was part of a larger corporate restructuring at PharmaCo. For the alliance with Beta, this event constituted a significant disruption with farreaching consequences. Not having been directly 
involved in the initial negotiations, PharmaCo's R\&D group was not aware of the origins and considerations around the alliance's founding history, and thus had little knowledge about and confidence in Beta's scientific expertise. Thus, the R\&D group was not familiar with the informally agreed-on arrangements and the overall spirit of the collaboration. Hence, various Beta representatives reported:

The deal was done with a certain group of people. And then everybody was happy, and life was grand. But then those people disappeared. They went off to do other things. The next set of people got stuck with what the first group of people had set up and understood. (Beta's Vice President of Research \& Development and Regulatory Affairs)

There was a difference between the PharmaCo people who negotiated the initial contract and the people who actually lived the contract. The folks that negotiated it were really not involved in executing and moved on. [...] It may be that the whole spirit of that negotiation was lost when those people moved on and new people [were] put in place. (Beta's Technical Director)

Thus, as noted by Beta's Chief Scientific Officer, "when that reorganization happened, things changed and spiraled downhill very rapidly." Virtually from the moment of relocation, PharmaCo's R\&D group interfered with Beta's development processes andcontrary to what had originally been agreed-exercised much more control. The interventions centered on questions of palatability and shelf-life issues, the use of certain active ingredients, reformulations, coding procedures, and the establishment of a scalable manufacturing process. Given that the alliance was based on a rather simple written contract, PharmaCo's R\&D group did not breach the formal contract. However, not having been involved in the alliance setup and therefore not having the institutional memory of the formation of the alliance, they did de facto violate the jointly developed spirit of the relationship and informally agreed-on rights and obligations-that is, the informal contract:

Those people who had that idea, who put in motion this flexible arrangement, they moved away. We were told that we were going to be protected from the R\&D people. The people who put the contract in place said that. (Beta's Vice President of Business Development and Marketing)

We felt that PharmaCo started to intentionally make changes or requests to our program that intentionally slowed us down. So, feelings of resentment built fairly quickly because they were not allowing us to do what we felt we signed up to do, which is to register products quickly. [...] It became almost like they were intentionally creating roadblocks for us to miss our milestones. [...] The changes that they wanted to do kicked us back in the milestone process, and they were definitely not part of the original spirit of the contract. (Beta's Technical Director)

Specifically, PharmaCo's R\&D group-feeling challenged by Beta and fearing a loss of their own reputation and influence-used, or rather imposed, its usual organizational routines, rigorous internal clinical requirements, and strict technical standards on the alliance. Over time, this made it increasingly difficult for Beta to follow its entrepreneurial scientific approach and apply its proven development procedures, which were geared toward fast development and FDA submission:

Many milestones had not been comprehensively defined, which allowed for different interpretations. [...] We consequently had debates on 'What is, actually, palatability? What is acceptable? What is $100 \%$ ? How is it measured?' [...] It ultimately turned out that the lack of contractual detail led to permanent discussions within the collaboration, since there have been ambiguities in regard to responsibilities. As a consequence, it quickly created tensions. (PharmaCo's Head of Technical Development, Animal Health North America)

However, difficulties arose related not only to ambiguities and conflict around the applicable rights and obligations but also to relational aspects of how to collaborate and work together. Notably, the initial interface of the alliance (that is, the formally agreed governance structures) was limited to periodic committee meetings. This decision was based on the intent that Beta, for the most part autonomously, would develop the new products by formulating the different active pharmaceutical ingredients in the drug delivery system. However, the new setting was characterized by extensive involvement of PharmaCo's R\&D group in Beta's development processes, so it demanded more reciprocal and simultaneous exchange:

What did not help was that we had one project manager here and one in the Netherlands. So, the communication, by the time it went through my project manager, through the Netherlands, back to the European headquarters, back to my team-it was just a major kind of communication disaster. (PharmaCo's Head of Development, Animal Health North America)

Managers and scientists at Beta became frustrated very rapidly. They not only got the impression that PharmaCo's R\&D group did not trust their expertise, but they also faced growing financial problems, because PharmaCo continually withheld authorization or postponed urgently needed payments for supposed milestone achievements.

They were constantly adding additional parameters to ongoing clinical studies, which is very frustrating. In 
other words, it felt like they were slapping us around a little bit and bullying us and expecting us to do all of these requests without question, without negotiation. [...] It created a tremendous disgruntlement among the Beta staff, from management all the way down to scientist level. [...] There was a point where we felt that we might have to walk away from this agreement. (Beta's Technical Director)

PharmaCo's R\&D group, on the other hand, felt that Beta had misrepresented their capabilities. They saw gaps in Beta's entrepreneurial scientific approach, questioned the true potential of their ADDS technology and feared that this proceeding would not lead to long-term, commercially viable products in accordance with PharmaCo's defined quality requirements. Moreover, they also got the impression that PharmaCo's senior management did not value their scientific expertise, because they were using an outside company to access innovation. Added together, the dissatisfaction and growing suspicion of Beta that was felt in PharmaCo's R\&D group even encouraged them to covertly launch parallel, inhouse development to secure some knowledge in case the relationship fell apart:

We have different requirements in the process. There were philosophically different approaches. [...] The simplistic scientific approach that Beta proposed made me question who it was on the PharmaCo team during the negotiation of the original contract. This should never have been accepted." (PharmaCo's Head of Development, Animal Health North America)

There was a real lack of trust. It was them making arbitrary decisions, without involving PharmaCo, and telling us later. They even made agreements with the FDA on our behalf that they knew we could not fulfill. (PharmaCo's Head of Global Development, Animal Health)

As a consequence, the alliance between PharmaCo and Beta was threatening to fall apart. A regulatory affairs manager at PharmaCo, for instance, noted that "there was a strong level of distrust between both organizations. It was very negative, very distrustful; nobody wanted to share information, and nobody wanted to talk to each other." Similarly, Beta's Head of Clinical Development reported that "the distrust reached a level where communication was not effective anymore. It came to a point where we were seriously considering a divorce."

\section{Analytical Interpretations of the Alliance Disruption Dynamic}

From a more abstract perspective, one can easily recognize the disastrous consequences brought about by PharmaCo's internal restructuring. During the first month of existence, the alliance's development was largely based on and supported by mutually agreed-on but uncodified rights and obligations (informal contractual mechanisms), as well as trust built during the negotiation meetings (informal relational mechanisms). PharmaCo's internal restructuring and the associated shift of personnel at the alliance interface constituted a significant disruption-that is, a change-inducing event that impaired both the informally agreed rights and obligations and the fragile web of social bonds between the parties. In fact, we observed that the initial setup of governance mechanisms-negotiated and established between PharmaCo's business development group and Beta-did not adapt to follow the changes in the partnership. In turn, it led to a substantial misfit between the governance mechanisms and the revised alliance setting-meaning that in the wake of the disruption, the governance mechanisms in place proved largely unable to properly govern the relationship.

The once promising collaboration was increasingly characterized by continuous conflicts and serious tensions-triggered primarily by a shift between how each side appreciated the formal and informal contracts-which ultimately resulted in deep distrust on both sides. In addition, contrary to the initial alliance setup that assumed a sequential type of interdependence (i.e., a relatively simple handover of new products from Beta to PharmaCo), the new setting and revised alliance scope entailed more reciprocal and simultaneous task interdependencies and thus required closer interaction and substantially more information exchange. Given the lack of appropriate governance mechanisms at this stage, the alliance was not only characterized by serious tensions; in addition, almost all projects suffered massive delays, required substantially more specific developments (including coordination with multiple downstream functions), and progressed much more slowly than initially expected. As a consequence, both partners were assessing possibilities of ending the alliance.

\section{Dynamic 2: Alliance Adjustment Triggered by Managerial Intervention}

As the initially highly promising PharmaCo-Beta alliance was characterized by increasingly severe conflicts, PharmaCo's corporate-level alliance management team was called in by the firm's senior management in order to prevent the alliance's increasingly probable termination. Aimed at rebuilding the collaboration, the alliance managers' intervention process was launched about two years after PharmaCo's internal restructuring had triggered disruption. It started with relationship-building meetings and collective problem-solving sessions. 
We went through the whole process of what is not working, what is working. We allowed ourselves to go through that whole process on what is not going well and what can be done to improve it. We sort of cycled through the issues and tried to come up with solutions. (Beta's Vice President of Business Development and Marketing)

The joint discussion led to the insight that many of the experienced difficulties stemmed from the structure and fundamentals of the alliance contract initially put in place between Beta and PharmaCo's business and development group:

We at PharmaCo felt that part of the reason the relationship was so bad was that there was not really mutual respect and the contract was mismatched. We knew that to get back on a footing that was workable, we would have to renegotiate the contract and rebuild the relationship. (PharmaCo's Head of Animal Health North America)

The intervention, and the following contract renegotiating process, eventually resulted in an amended contract that both sides signed in December 2013. This new contract included detailed product profiles, comprehensive development and cost plans, fundamental definitions, and specified criteria for achievements. In fact, the new contract, which included nearly three times more pages than its former version (170 pages compared with 55), did not feature a large increase of contractual clauses but instead more detailed specifications of existing ones - in particular, in the areas of product development and payment details as illustrated by this excerpt from the amended contract:

Palatability trials (CM and NM) will be managed by Beta. Those trials will be run using the protocol attached (Annex C) using Final Formulation. Beta will be paid CRO rates for managing the trials and all palatability work shall have been included in the Project Cost Plans. The Parties agree that conducting a single trial is the target and, if another trial is required, Beta may invoice PharmaCo for the costs. [...] Flavorings and excipients that meet applicable regulatory requirements in the US and EU for use in pharmaceuticals can be used (including animal flavorings) in their respective US and EU markets. Beta will use its best efforts to utilize non-animal flavorings and provide the necessary palatability. Solvents and coatings must meet applicable regulatory requirements in the US and EU for use in pharmaceutical solvents and coating. (Excerpt from the amendment to the assignment and license agreement)

Under the new contract, Beta gained more financial security by receiving a guaranteed service fee. In turn, PharmaCo got more control over the development process as its R\&D group became empowered to specify comprehensive requirements for Beta's development efforts. PharmaCo's Head of Technical Development explained:

We circumstantiated a product profile for every development product, in which we laid down must haves and nice to haves. We defined what is really acceptable and what is not. It helped in the discussions, since we did not fight any more about what the expectations really are.

In this spirit and reflecting the R\&D group's stance toward the partnership, the overall focus, forms of checks and balances, and incentive schema of the alliance consequently shifted from a one-sided focus on fast submissions to the FDA agency, toward quality registration and the actual commercial launch of marketable, long-term sustainable products.

The arduous renegotiation process, however, did not only yield a more elaborated formal contract; both parties also accommodated the increased need for coordination and relationship building by instating an on-site project manager and agreeing on an intense use of joint committee meetings:

We wanted more transparency in the development and that we discuss important steps jointly. We organized expert meetings, subteam meetings and so on, in which the experts really get together and discuss these issues. (PharmaCo's Head of Technical Development, Animal Health North America)

This change was seen as essential, as the restructuring at PharmaCo had not only impaired the originally established social bonds between the partners but also caused considerably more interdependencies-thus precipitating the need for more defined coordination structures. After the amended agreement came into force, the PharmaCo-Beta alliance made rapid progress. The first products were launched and both parties worked more closely together. As Beta's Chief Scientific Officer explained:

Under the new agreement, things are running much more smoothly. I think we are much more efficient and productive. We are back to being happy with the alliance. [...] I think the alliance today is in really good shape and, going forward, I think we have a very bright future together. [...] I think the alliance is sort of almost miraculous, the progress we made since we resigned the alliance on a new agreement-it has been really quite remarkable to me.

PharmaCo's Head of Global Development likewise observed: "the new contract helped toward aligning the goals, but it also provided the framework for constant communication to really start [to] develop trust."

\section{Analytical Interpretations of the Alliance Adjustment Dynamic}

Although the intervention by PharmaCo's alliance management group and the initiated adjustment of 
the alliance prevented the imminent downfall of the partnership, it is worthwhile to have a closer look at how this event specifically impacted the use and functionality of the governance mechanisms in place. Most notably, the adjustment process yielded a considerably more detailed formal contract that laid the foundation to revitalize the alliance by realigning expectations and clearly defining and formally documenting the rights and obligations of each party. Furthermore, benefiting from the fact that the partners had, over time, developed a solid understanding of the development and registration process, their respective competencies, as well as the nature of interdependence and precise fulfillment of task, they set up and implemented several formal relational mechanisms to clarify decision making processes, facilitate information exchange, and meet the increased coordination requirements. Furthermore, the detailed specification of formally documented product profiles helped to align expectations and to mitigate conflicts over technical issues. In sum, the alliance governance structure-which at the outset of the partnership had relied heavily on informal mechanisms-shifted to a reliance on formal governance mechanisms. Notably, when assessing not only the quality of the relationship but also the outcomes in respect to the technical and commercial success, the PharmaCo-Beta alliance was functioning much more effectively after the adjustment.

Overall, the evidence indicates that at the outset of the alliance the partners did not have a sufficiently clear understanding of the alliance's scope and objectives because of the uncertain nature of the R\&D activities involved (Period 1). Reliance on informal contractual and informal relational mechanismssupported by the setup of formal relational mechanisms-appeared as adequate given those uncertainties and the intention to speed up drug development. The internal restructuring at PharmaCo (Triggering Event 1) constituted a distinct turning point. Leading to a marked disruption of the relationship (Dynamic 1), the alliance was then on the edge of collapse because the governance mechanisms in place were not well suited for the new situation (Period 2). However, thanks to the subsequent intervention by PharmaCo's alliance management group (Triggering Event 2), and a redesign of the governance structure, the alliance could be adjusted (Dynamic 2) and ultimately once again set on a viable developmental path (Period 3).

\section{Discussion}

In this section, we first discuss how the revised typology of alliance governance mechanisms that we propose serves as a lens to explain the observed dynamics, in contrast to the prevailing unidimensional distinction between contractual versus relational mechanisms; we also analyze the tradeoffs inherent in the alliance's ruling principles that governance mechanisms encompass. Second, we develop propositions that capture our key conceptual insights in relation to how those tradeoffs-and consequently the value of alliance governance mechanisms - change through disruption and adjustment dynamics. Finally, we theorize how the interplay between different types of governance mechanisms evolves following disruption and adjustment.

\section{Alliance Governance Mechanisms and Their Inherent Tradeoffs}

We started our analysis of the PharmaCo-Beta alliance from a revised typology of alliance governance mechanisms (Table 1) that integrates two dimensions of governance mechanisms: the means to enforce these ruling principles (i.e., contractual versus relational mechanisms) and the level of codification of the ruling principles that governance mechanisms encompass (i.e., formal versus informal mechanisms). First, our findings allow us to go beyond the common association in the governance literature between contractual and formal mechanisms (Poppo and Zenger 2002, Howard et a. 2019). We observed that the legally enforceable agreement between PharmaCo and Beta contained both written and oral parts. This observation is consistent with the textbook definition of a contract as an agreement that is legally enforceable, irrespective of whether the agreement is made orally or captured in writing (Chen-Wishart 2012, Cross and Miller 2012, Furmston and Tolhurst 2016, Mann and Roberts 2018). ${ }^{8}$ It also echoes Ring (2008) who noted "economists generally assume that the contracts they describe will be written. But legally enforceable contracts can be oral. (...) [S]ome parties to IOEs [interorganizational entities] might be inclined to make verbal agreements and to operate on the basis of handshake" (p. 9). As such, contractual governance may be both formal and informal; indeed, we observed that some of the mutual promises defining the rights and obligations of the parties were codified while others remained uncodified. Although this insight follows the legal definition of contracts, as well as early observations (Macaulay 1963), alliance scholars have focused on the formal aspects of contracts (Ryall and Sampson 2009, Malhotra and Lumineau 2011), largely ignoring their informal component.

Second, our study also points out that relational mechanisms are not necessarily informal. The PharmaCo-Beta alliance includes a number of relational elements that were codified by the parties. For example, the conditions for the exchange of personnel were codified in a formal document. However, these 
aspects were not part of the official contract (i.e., the assignment and license agreement) between PharmaCo and Beta, and they were not (easily) enforceable by law. Moreover, various other shared documents, such as committee meeting minutes and project plans, were used to structure and coordinate the relationship. These documents codified patterns of behavior that partners expected from each other. In contrast to the dominant approach in the literature (Dyer and Singh 1998), our study indicates the need to avoid assuming a systematic and direct correspondence between relational and informal governance mechanisms.

In addition, our analysis highlights some tradeoffs inherent in the various governance mechanisms. These tradeoffs stem from the benefits and drawbacks entailed in the dimensions that underlie the revised typology. The first dimension relates to the means of enforcing the ruling principles. On the one hand, the benefits from legal enforceability relate to the assurance that a third party will protect the partners' interests as captured in contracts. Given the stakes involved in an alliance such as the one we studied, the ability to enforce the promises made by the parties is a critical factor. In particular, at the core of contracts (either formal or informal) lies a set of mutual promises defining the rights and obligations of the parties. A right or obligation is enforceable in the courts if a party obligated to act in a particular way can be forced or ordered to comply with the legal process (Furmston and Tolhurst 2016). On the other hand, the drawbacks of contractual mechanisms relate to the negative signal that may be conveyed by establishing recourse to a third party for solving possible conflicts. As such, formal contracts may, in fact, undermine the alliance by fueling conflicts among parties and encouraging, rather than discouraging, opportunistic behavior (Macaulay 1963, Van de Ven and Walker 1984). These governance devices are likely to be perceived as unnecessarily constraining and inflexible (Volberda 1998). A focus on mechanistic rules may lead the parties to feel coerced into complying with a particular behavior. In contrast, the benefits from self-enforceability stem from the absence of such a negative signal, while the drawbacks relate to the possibility that breaching the agreement becomes an attractive opportunity.

The second dimension underlying the revised typology of alliance governance mechanisms relates to the level of codification of the ruling principles that the mechanisms encompass. On the one hand, the benefits from codification relate to the ability of formal mechanisms to serve as knowledge repositories. Partners may need to regularly check the specific conditions of their agreement. Formal mechanisms prove particularly useful for documenting what the parties have agreed to and supporting the organizational memory over time (Mayer and Argyres 2004, Lumineau et al. 2011). On the other hand, the drawbacks of codification relate to the costs when terms need to be clarified in writing. This is an issue that has been widely discussed, especially by transaction cost theory regarding the costs of drafting and monitoring formal contracts (Williamson 1985). In fact, as our findings suggest, the formal elements of governance tend to be more expensive to develop, implement, and manage than informal ones. The process of formalization itself is time consuming (Vlaar et al. 2007, Ariño et al. 2014) and often requires the involvement of experts. Other types of written rules that govern a relationship - such as the formal definition of roles and responsibilities, decision and control rights, communication terms (Argyres and Mayer 2007), or technical elements (Vanneste and Puranam 2010) —are also costly to devise and implement (Hoetker and Mellewigt 2009) and may involve costly professional services, such as those provided by lawyers (Argyres and Mayer 2007). In contrast, informal governance mechanisms are less costly upfront than formal mechanisms. The fact that informal mechanisms are not codified allows parties to avoid the costly and timeconsuming process of articulating with precision the different facets of their collaboration in writing. As in the case of the PharmaCo-Beta alliance, the use of informal contractual governance offers collaborating parties a suitable means to reach a swift and flexible agreement and to timely start an alliance. This advantage may be particularly decisive in uncertain and dynamic settings, such as R\&D alliances, which cannot be completely prestructured and in which speed and time to market are crucial for commercial success. However, we observed that the same lack of codification easily leads to potential misunderstandings, which often generate costs and efforts during the subsequent implementation.

In sum, a detailed examination of the PharmaCoBeta alliance highlights several tensions and inherent tradeoffs between the four different governance mechanisms (i.e., enforceability versus perceived signaling of intentions; knowledge repository versus codification costs). It is worthwhile to mention that prior studies have generally focused on a subset of these tensions between a subset of mechanisms to understand the substitution versus complementarity debate. Although we do not argue that these tensions are exhaustive, our analysis suggests their importance for better understanding the dynamics at play in alliances. 


\section{Contingent Value of Alliance Governance Mechanisms in the Face of Disruption and Adjustment}

Our analysis of the PharmaCo-Beta alliance highlights how the benefits and drawbacks of each type of mechanism depend on specific dynamics (see Table 6 for an overview of alliance governance mechanisms' inherent tradeoffs through disruption and adjustment). Based on our longitudinal analysis, we develop propositions about the evolution of the value of each of the four types of governance mechanisms. We organize our arguments around the two major dynamics we observed: (1) the disruption triggered by internal restructuring and (2) the adjustment triggered by the managerial intervention. We observed that the drawbacks and benefits of the various mechanisms changed over the course of the alliance. Importantly, these changes resulted from two concurrent but distinct effects. On the one hand, a naturally occurring effect unfolds over time as partners learn about each other and their alliance (e.g., scope, tasks, contingencies). On the other hand, in the case of the PharmaCo-Beta alliance we observed that disruption and adjustment noticeably affected those benefits and drawbacks.

As for formal contractual mechanisms, prior research has shown that negotiating and drafting a formal alliance contract is a laborious, costly and highly time-consuming process that requires the involvement of experts (especially lawyers) to deal with the technicalities of phrasing, writing, and approving the legal document (Sampson 2002). Given that the partners of the PharmaCo-Beta alliance want to reach a swift agreement and set up a flexible structure that promoted rapid product development, they deliberately refrained from spending too much time on negotiating and fine-tuning the wording of a lengthy alliance contract. This decision was supported by the fact that the alliance task and the partners' respective contributions, roles, and responsibilities were not entirely defined and thus were difficult to clarify and formally record in every detail at this early stage. In other words, at the outset, the alliance was characterized by a high degree of uncertainty regarding its actual scope, which limited the partners' ability to make use of formal contractual governance. In addition, the two main benefits of formal contracts-their capacity as a knowledge repository and their legal enforceability-were not considered highly critical at that point. Instead, the emphasis was on speed, flexibility, and the development of a cooperative spirit. However, as the alliance underwent disruption, the two main benefits of formal contracts progressively became more important. For instance, it was only after PharmaCo's restructuring that the partners started to review the formal contract, which until then had barely been considered, in order to have tangible proof of previous decisions. It follows that at this stage, the formal contract was seen as a reference document used to support the memory of the involved parties and to evaluate if one of the partners was breaching the official agreement in place. In particular, given the changes and turnover of personnel at the alliance interface, the contract became increasingly relevant as a knowledge repository. This observation suggests that the formal contract really gained importance as the alliance underwent disruption and the partners experienced tensions and therefore began to check who was right and what was initially agreed. We thus suggest the following.

Proposition 1a. In an RED alliance undergoing disruption, formal contractual governance mechanisms go from marginally beneficial to beneficial.

We also noted a shift in the value of formal contractual mechanisms in the course of the adjustment. At the outset of the alliance, both parties had intentionally reduced their reliance on the formal contract to keep the relationship flexible, to spur entrepreneurial product development and to signal goodwill. This insight echoes prior research suggesting that too much contractual formalization may be harmful and cause rigidity (Vlaar et al. 2007) and that by focusing on the monitoring and scrutiny of the partners' activities, formal contracts may sow the seeds for mutual suspicion and behavior watching, send negative signals, and tamp down entrepreneurial behavior (Sitkin and Roth 1993, Ghoshal and Moran 1996, Lumineau 2017). However, in contrast to prior research, which tends to make this argument in a crosssectional manner, we observed that this effect was particularly strong at the outset of the alliance when the partners were highly uncertain about their counterpart's motivations and intentions but did not prevail during and after the adjustment. Instead, in the wake of the intervention, the renegotiated formal contract was used and considered as an important sign of commitment to the continuity of the alliance. As such, the formal contract then changed from a source of suspicion to a positive signal of assurance for the future of the alliance. Furthermore, over the course of the adjustment, the partners were able to reap the benefits of contractual learning (Mayer and Argyres 2004, Lumineau et al. 2011). Over time, PharmaCo and Beta had gained a better understanding of their respective needs and competencies, structural and cultural idiosyncrasies, task interdependencies, and the exact coordination requirements and priorities of the alliance. Thus, they were able to more easily negotiate and draft a detailed formal contract, which was facilitated through intensive renegotiations (Reuer 


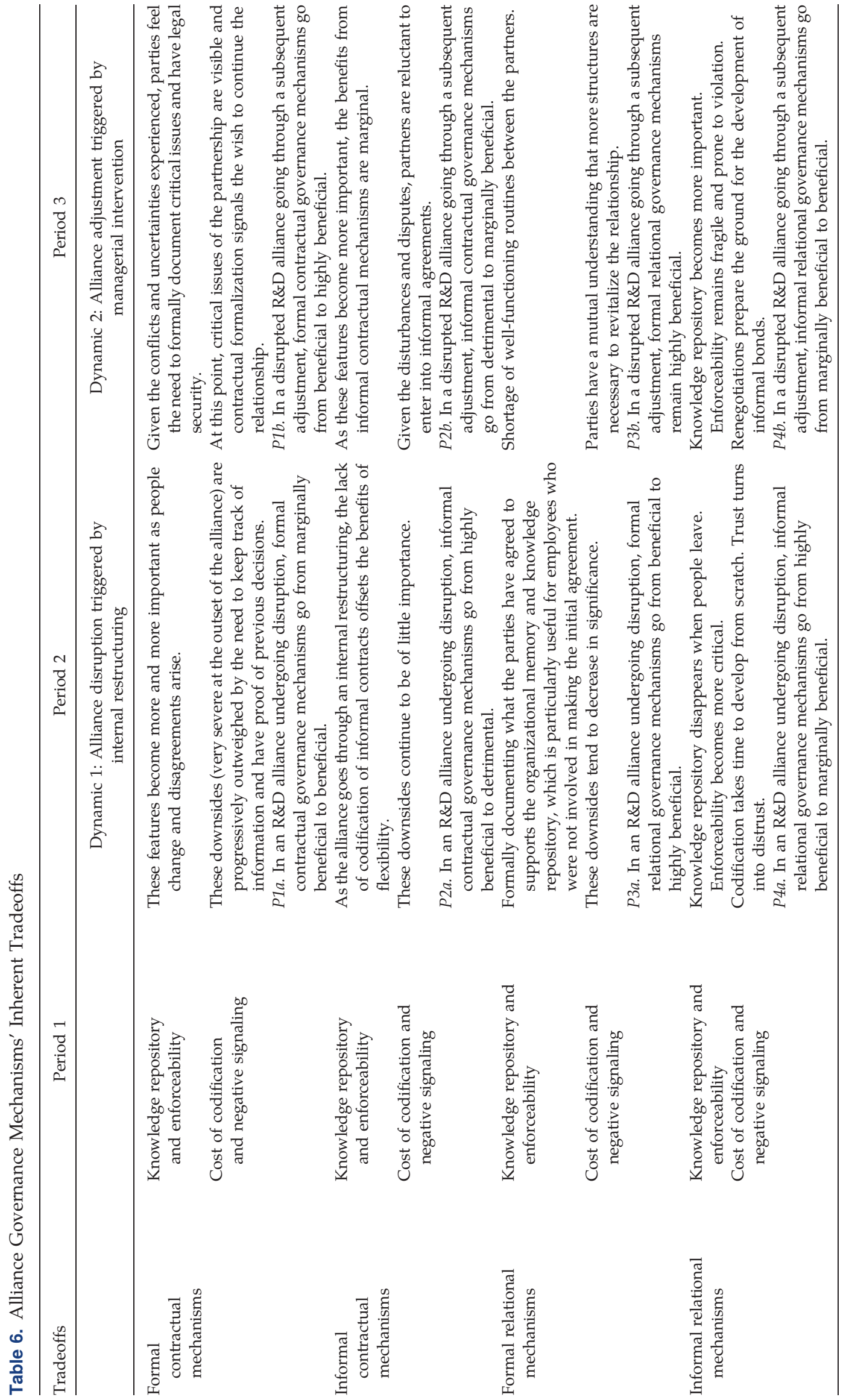


and Ariño 2002) that helped the partners gain a more precise idea and joint understanding of the critical contingencies around their relationship. In addition, given the tensions and uncertainties that both parties had experienced, they both felt the need to formally document and back up critical issues with legal security. As such, although the formal contract's benefits (knowledge repository and legal enforceability) increased and its associated drawbacks (cost of codification and negative signaling) waned over the course of the disruption, formal contractual governance mechanisms turned out to be highly beneficial during adjustment. Therefore, we suggest the following.

Proposition 1b. In a disrupted RED alliance going through a subsequent adjustment, formal contractual governance mechanisms go from beneficial to highly beneficial.

Turning to informal contractual mechanisms, we observe different dynamics that affected their relative benefits and drawbacks. As we pointed out in our case analysis, informal contracts tend to be relatively easy to develop as they do not undergo the scrutiny of legal teams-which lends them flexibility. This was particularly appreciated at the beginning of the alliance when PharmaCo and Beta were eager to quickly launch an entrepreneurial collaboration. Both partners not only aimed for a rapid agreement to bring the products to market as soon as possible, they also intentionally reduced the degree of formal contractual detail to be more flexible and to benefit from Beta's entrepreneurial development approach. Thus, as the setup and formation of an alliance is generally an endeavor involving a great deal of uncertainty and ambiguity (Doz 1996, Kale and Singh 2009), the use of informal contractual governance promotes flexibility and allows for effectively coping with partner and task uncertainty and changing environmental conditions (Macneil 1978, Ring and Van de Ven 1992). By quickly adjusting their agreement, partners can thus overcome the "strait-jacketing effect of [formal] contracts on adaptation" (Carson et al. 2006, p. 1059), avoiding expensive renegotiation and adjustment costs and speeding up the fulfillment of collaboration tasks. We also noticed in our analysis that the informality was perceived as a sign of trust and good intentions between the new partners. In contrast, extensive use of formal contracts may give a firm a reputation for being bureaucratic and legalistic (i.e., focused on knowledge protection and value appropriation) instead of entrepreneurial and collaborative (i.e., focused on knowledge sharing and joint value creation).

Although informal contractual mechanisms proved highly beneficial at the outset of the PharmaCo-Beta alliance, during the disruption their lack of codification and costly legal enforceability offset their benefits of flexibility. As we observed in our case study, oral agreements typically have loose ends and lack verifiability; relying on informal contractual mechanisms opens the door to disagreement about the interpretation of the content of the informal contract. For instance, during the disruption in the PharmaCo-Beta alliance, there were different understandings about the original informal agreement, which led to serious conflicts and dissatisfaction on both sides. Reliance on informal contracts proved particularly detrimental, given personnel turnover when the alliance transitioned. As individuals who did not participate in the alliance negotiations and launch took charge, overcoming misunderstandings and conflicts around the content of the informal contract became more challenging. The new personnel did not have access to the informal deal discussed at the outset, which made its legal enforcement more difficult and costly. Therefore, our study highlights the importance of the stability of interpersonal relationships for the proper functioning of informal contractual governance mechanisms. We hence propose the following.

Proposition 2a. In an RED alliance undergoing disruption, informal contractual governance mechanisms go from highly beneficial to detrimental.

Although informal contractual mechanisms had caused considerable problems and thus proved detrimental during the disruption experienced by the PharmaCo-Beta alliance, they became marginally beneficial over the course of the adjustment triggered by the PharmaCo alliance management group's intervention. This adjustment was characterized by more continuity in personnel and fewer uncertainties, misunderstandings, and conflicts. However, while not negatively affecting the alliance's viability anymore, we observed that the partners were reluctant to rely on informal contractual mechanisms again to manage their relationship. The disruption had dramatically revealed the downsides of informal agreements. In view of the experienced problems, both parties thus preferred to avoid any risks and formally codify as many critical issues as possible. Furthermore, given that the alliance partners, in contrast to the initial phase, had gained a more comprehensive understanding of the alliance tasks and critical contingencies at this point, the benefits of informal agreements (e.g., in terms of lower costs of codification) had largely disappeared. After suffering from the limitations of informal contractual mechanisms in the wake of the disruption, both PharmaCo and Beta preferred to focus their efforts on rebuilding the alliance on and through a formal contract.

Proposition 2b. In a disrupted RED alliance going through a subsequent adjustment, informal contractual governance mechanisms go from detrimental to marginally beneficial. 
Formal relational mechanisms are mutually agreed-on and written means to structure the relationship through, for instance, rules for exchanging personnel and making decisions as well as fulfilling procedures. As we observed at the outset of the alliance, a codification of rules and procedures allows parties to clarify their expectations about patterns of behavior and thus minimize the risk of misunderstandings (Vlaar et al. 2007, Lumineau 2017). Formally documenting what the parties have agreed on also supports the organizational memory and knowledge repository over time, which is particularly useful during a disruption for employees who were not involved in making the initial agreement. This type of mechanism shares the advantages of formal contracts for codifying mutual expectations between organizations (Mayer and Argyres 2004) and tends to become very beneficial when partners go through a disruption and the informal mechanisms prove insufficient. We therefore suggest the following.

Proposition 3a. In an RED alliance undergoing disruption, formal relational governance mechanisms go from beneficial to highly beneficial.

During the adjustment, formal relational mechanisms became highly beneficial. As the partners were trying to relaunch the alliance during the phase of intervention, this set of codified patterns of behavior proved immensely helpful for fostering the exchange of information and coordinating activities between PharmaCo and Beta. As an illustration, the minutes of the meetings were used as written documents to track decisions and future actions of each partner. As the parties went through the adjustment phase, they both saw a lot of value in these formal documents and their capacity to revitalize the relationship. We thus propose the following.

Proposition 3b. In a disrupted RED alliance going through a subsequent adjustment, formal relational governance mechanisms remain highly beneficial.

As for informal relational mechanisms, we observed that although they remained overall beneficial over the course of the alliance the disruption and the subsequent adjustment markedly changed their relative benefits and drawbacks. Although informal relational mechanisms prove highly beneficial in the initial phase of an alliance (e.g., by signaling good intentions), these mechanisms usually depend on specific individuals involved in the setup of an interorganizational relationship (Schilke and Cook 2013). This is especially true in the early stages, when informal relational mechanisms connect specific people rather than the entire organization. As such, given that at the outset of an alliance these mechanisms typically do not go beyond the narrow circle of people directly involved in negotiating the alliance, these trusting relationships tend to be highly fragile and vulnerable to disruptions and discontinuities. As we observed in the PharmaCo-Beta alliance, trusting relationships were quickly destroyed and lost value when the individuals in charge of negotiating, forming, and operating the alliance left during the internal restructuring. Although social bonds between PharmaCo's business development group and Beta literally disappeared, the new relationship between Beta and PharmaCo's R\&D group was characterized by unclear expectations, misunderstandings, and steadily growing conflicts. Given the high level of uncertainty after a disruption, informal relational mechanismswhich are particularly inadequate to store knowledge-tend to prove less beneficial in governing a relationship. We therefore propose the following.

Proposition 4a. In an RED alliance undergoing disruption, informal relational governance mechanisms go from highly beneficial to marginally beneficial.

Although the relationship between PharmaCo and Beta was full of conflicts and close to failing immediately after the disruption, the intervention and commitment demonstrated by PharmaCo's alliance management group was able to reset the partnership by adjusting the overall setup of the alliance. As for informal relational mechanisms, the intervention was important for redressing suspicion and distrust and establishing the foundations for rebooting trust. This observation echoes the literature on the role of interventions in promoting and repairing trust between partners and cultivating seeds of a revival of informal bonds (Gillespie and Dietz 2009, Brattström et al. 2018). As the alliance went through the adjustment that involved various meetings and open debates in which partners solved conflicting issues and thus expressed and realigned their expectations, the slowly strengthening informal relational mechanisms proved useful for enabling and facilitating extensive communication and information sharing on a flexible basis in the renegotiations and the subsequent resumption of operations (Ring and Van de Ven 1992, Dyer and Singh 1998). Nonetheless, given the problems encountered before the adjustment, a "shadow of the past" prevailed. As such, even though informal relational mechanisms became beneficial, they proved relatively hard to reboot and were characterized by a certain degree of caution and skepticism. Thus, we suggest the following.

Proposition 4b. In a disrupted RED alliance going through a subsequent adjustment, informal relational governance mechanisms go from marginally beneficial to beneficial. 


\section{Dynamic Interplay of Alliance Governance Mechanisms}

An important insight of our case analysis is the evolution of the tradeoffs inherent in the various types of governance mechanisms as the PharmaCoBeta alliance went through disruption and adjustment. Typically, interorganizational relationships rely on a combination of governance mechanisms (Bradach 1997), thus understanding how these mechanisms interact is a critical issue. Although prior research has begun to study the dynamics of governance mechanisms over time, it has largely overlooked how the interplay of governance mechanisms is affected by disruption and subsequent adjustment. In what follows, we develop propositions suggesting that the interplay of governance mechanisms is also dynamic. Our goal in this section is not to discuss each possible combination of governance mechanisms. Instead, in order to keep our analysis tractable, we focus our discussion on what we believe departs from the existing literature on alliance governance.

In light of the previous arguments, we suggest that formal contractual and informal contractual governance mechanisms function as substitutes over the whole course of the alliance. As shown in the analytical interpretation of the alliance formation, at the outset informal contractual mechanisms tend to be beneficial, because they reduce the costs of codification and send positive signals. The strength of formal contractual mechanisms (i.e., knowledge repository and legal enforceability) is not critical at this point. Therefore, informal contractual and formal contractual governance mechanisms largely replace each other in defining the rights and obligations of the parties. Our case analysis suggests that following a disruption, formal and informal contractual mechanisms remain substitutes for each other, but the drawbacks of informal contractual ones in terms of serving as a knowledge repository and the difficulties they pose regarding legal enforceability become salient. It is then beneficial to expand the formal contract. In fact, the parties in our case substantially increased the length of their contract. At this point of the alliance, the formal contract as a knowledge repository is more valuable and the costs of codification are much lower than at the outset. Consequently, the value of informal contractual mechanisms will be replaced by formal contractual ones. Therefore, we propose the following.

Proposition 5a. In an RED alliance undergoing disruption, formal contractual and informal contractual mechanisms remain substitutes.

Proposition 5b. In a disrupted RED alliance going through a subsequent adjustment, formal contractual and informal contractual mechanisms remain substitutes.
Next, we suggest that the reliance on formal relational governance mechanisms fosters information exchange through, for instance, the establishment of committees, working groups, and the exchange of personnel. In this way, they spur strong social interactions, which lay the foundation for the beneficial development of informal relational governance (i.e., trust and expected behaviors). Formal relational governance creates the conditions that facilitate informal relational mechanisms, which in turn makes the formal relational ones more effective. Therefore, they complement each other. However, as demonstrated in the case, following disruption entailing replacement of personnel, trust and the expectations of partners' future behavior and activities vanish. Consequently, this shift undermines the effective functioning of formal relational governance mechanisms (i.e., the substitution effect). After the alliance management team's intervention, the adjustment of formal relational mechanisms allowed for the exchange of information about the precise goals and scope of the alliance. This provided a novel foundation on which to build trust among the new people involved. As at the beginning, formal relational and informal relational mechanisms facilitated each other and functioned as complements to one another.

Proposition 6a. In an RED alliance undergoing disruption, formal relational and informal relational mechanisms go from complements to substitutes.

Proposition 6b. In a disrupted RED alliance going through a subsequent adjustment, formal relational and informal relational mechanisms go from substitutes to complements.

Based on our empirical analysis, we argue that informal contractual and informal relational governance mechanisms complement each other at the outset of the alliance. As we have shown, informal contractual governance mechanisms are flexible, have time and cost benefits, and send signals of trust. These benefits are especially valuable, as demonstrated in the case analysis, early in the alliance because of the uncertainties that abound at this stage. The initial reliance on informal contractual mechanisms, even if fragile, sends positive signals of trust toward the alliance partners. Therefore, informal contractual mechanisms enable informal relational ones. However, in our case study, the loose ends of informal contracts led to misunderstandings and conflicts between the partners following the disruption. As such, the informal contractual mechanisms mitigated the informal relational ones. Steadily decreasing levels of trust, in turn, negatively influenced the informal contracts as partners got more suspicious over time. Thus, both mechanisms developed in a negative loop. 
Proposition 7. In an RED alliance undergoing disruption, informal contractual and informal relational mechanisms go from complements to substitutes.

\section{Conclusion}

This study contributes to a dynamic perspective on alliance governance by examining the impact of disruption and the subsequent adjustment on the value of alliance governance mechanisms. Our in-depth analysis of the governance dynamics of the PharmaCo-Beta alliance suggests that the value of governance mechanisms can be substantially altered through disruption and subsequent adjustment dynamics. On the basis of our findings, we (1) show the significance of a more finegrained typology of alliance governance mechanisms which suggests that contractual governance is not necessarily formal and relational governance is not necessarily informal; (2) provide a more systematic discussion of the tradeoffs, (i.e., the benefits and drawbacks) that the various mechanisms entail and how these are altered through disruption and adjustment dynamics; and (3) analyze how the interplay between different types of governance mechanisms evolves following disruption and adjustment. Therefore, our study suggests that the value of both the individual and combination of alliance governance mechanisms does not follow a path of linear development (see also Vanneste et al. 2014) but may be subject to marked changes over the course of a relationship. In fact, we suggest that different mechanisms may operate as both complements and substitutes at different points in time in the same alliance. Following our contingency perspective, alliance governance can thus be regarded as the dynamic management of the underlying benefits and drawbacks of different governance mechanisms over the course of a relationship, rather than a static consideration about their universal nature and interplay.

This study also entails important managerial implications. First, our analysis suggests that alliance partners have more nuanced design choices to structure and govern a relationship than previously assumed. Second, managers, engineers, and lawyers who are involved in alliances should carefully consider the specific benefits and drawbacks of each governance mechanism. Our analysis indicates several inherent tradeoffs of each mechanism, especially concerning legal enforceability, costs, organizational memory, and negative signaling. In particular, our study demonstrates the need to manage and balance different combinations and sequences of governance mechanisms not only at the outset but also over the course of time and, in particular, following a disruption. We thus specifically encourage alliance managers to develop a temporal and context-dependent awareness for the usage of different governance mechanisms. Third, our analysis provides guidelines on how to combine different governance mechanisms and avoid using several functionally equivalent mechanisms at the same time in order to reduce the risk of inefficiency and redundancy. Last, although changes of key personnel are ubiquitous in alliances (Doz 1996, de Rond and Bouchikhi 2004), collaborating parties are advised to take specific actions to preserve the informal side of alliance governance (e.g., maintaining managers responsible for boundary-spanning or else holding specific handover sessions). Specifically, as our empirical analysis has revealed, interorganizational relationships based on high reliance on informal mechanisms are likely to be vulnerable in cases of discontinuity and lack of consistency at the alliance interface.

We need to underscore that our study was possible thanks to the unique access we were granted to rich longitudinal data about the governance dynamics at the PharmaCo-Beta alliance, provided by key decision makers of both parties. At the same time, we acknowledge that a single case study faces limitations, as the specific nature and context of the case represent boundary conditions to its analytical generalizability (Busse et al. 2017). Although we studied an archetypical alliance in a well-established industry setting, the study's insights-aiming for analytical, not statistical, generalization (Yin 2014) — can be generalized to theory, not to the population. We encourage future research to further refine and explore the scope of our theorizing and to determine to what extent the study's insights are transferable to both similar as well as different settings. In turn, expanding these limits provides opportunities for further advancing our understanding of how disruption impacts alliance governance. One first step would be to confirm with quantitative evidence the prevalence of the four governance mechanisms depicted in the typology that we have proposed. Different mechanisms may be more or less widespread across different relationship types, industry settings, or countries.

Additionally, we see several promising avenues for future research on alliance disruption dynamics. First, the disruption in our case was triggered by an internal restructuring in one partner company which involved a substantial change of key personnel at the alliance interface. We acknowledge that such partnerspecific events related to a partner's organization may be particularly disruptive for an alliance's governance mechanisms, as they tend to discontinue the established social linkages and informal agreements are therefore lost. We believe that our theorizing may be extended to other forms of disruption to the extent that they also significantly impair the social aspect and human component of alliance management. For example, in some cases, a firm's business development group establishes a partnership and sets up its 
contract to then transfer it to an operative unit-thus bringing about a change of interface personnel. Such incidences may have a similar impact as an internal restructuring would on the value of the governance mechanisms in place. However, as discussed in our overview of research on disruption in interorganizational relationships, other situations may cause disruption; we therefore encourage future studies to probe the applicability of our propositions to other categories of disruption. It might be, for instance, that disruptions triggered by external events-such as pandemics, terrorist attacks, wars, or natural disasters-that happen beyond the partnering organizations and hence tend to "have a similar impact to all the parties to a collaboration" (Bruyaka et al. 2018, p. 449) strengthen the value of informal relational governance by leading alliance partners to rally around a greater cause and display empathy and understanding. At the same time, such disruptions may weaken the value of formally agreed contracts and discourage, for example, a strict enforcement of penalty provisions related to delay or delivery failures. Second, we studied an $R \& D$ alliance in a segment of the pharmaceutical industry. Given the typically fierce time-to-market pressure, considerable partner and task uncertainty, and the relatively long time horizon of this industry, this type of partnership is particularly exposed to potential disruption. Whether alliances in similar settings, such as in software and information technology (Mayer and Argyres 2004), and in different industries or alliances of a different nature-for example, purchasing, marketing, or production alliances-are equally affected by disruption is up to future investigation. Third, the partners in our case operated in the United States and Western Europe, both of which enjoy strong legal systems even if in different regimes. When using contractual mechanisms to govern alliances, the parties are dependent on the enforceability in the legal system (Achrol and Gundlach 1999, Zhou and Poppo 2010). Thus, the effectiveness of those mechanisms depends heavily on the institutional environment and, in particular, on the quality of the country's legal system (Oxley 1999, Zhou and Xu 2012). Fourth, the alliance we studied was a crossborder alliance between two unequally sized firms, which may have led to misunderstandings that made the disruption even more consequential. Whether differences in size or culture influence the impact of disruption is worth studying. Last, we analyzed a nonequity alliance that proved very vulnerable to disruption. Future research could investigate how disruption impacts the value of governance mechanisms in equity alliances or joint ventures (Inkpen and Beamish 1997).

In conclusion, this study has brought the concept of disruption to the dynamic perspective on alliance governance. While stimulating research on alliance governance dynamics, we also hope that our insights may help managers in developing awareness of the context dependence of alliance governance mechanisms' value and hence assist them in making better governance choices both at the outset of their alliances and in the wake of disruption.

\section{Acknowledgments}

This article is the result of the joint effort of the team of authors, and it has benefited from helpful feedback received on earlier versions. The authors are grateful for valuable insights and guidance from senior editor Gino Cattani and two anonymous reviewers. The authors thank Kyle Mayer, Nuno Oliveira, and Jörg Sydow for helpful feedback on previous drafts. The authors benefited from thoughtful comments by participants at the 2017 Academy of Management Annual Meeting, the Strategic Management Society Special Conference in Costa Rica, and the Entrepreneurship and Collaboration Conference, University of Colorado Boulder, as well as at seminars at Alpen-Adria Universität (Austria), Chinese University of Hong Kong (China), ESADE (Spain), Fundação Getúlio Vargas (Brazil), Freie Universität Berlin (Germany), HEC Paris (France), IESE Business School (Spain), Insper (Brazil), Lingnan University (China), Toulouse Business School (France), University of Geneva (Switzerland), and University of Hong Kong (China). The authors also thank the individuals who made access to the data possible.

\section{Endnotes}

${ }^{1}$ This table is based on an extensive search of the literature. First, we systematically searched for articles published in the last 30 years (1990 to September 2020) in the Web of Science using the term "disrupt ${ }^{* \prime}$ in their title or abstract. Notably, we extended our search to include potential synonyms of the phenomenon of disruption: specifically, we included "disturb*," "interrupt*," "discontinu"," and "instability." In order to get a broad overview and to reflect the diversity of interorganizational relationships, we connected these terms with the following keywords: "alliance," "partnership," "collaboration," "relationship," "interfirm," "inter-firm," "interorganizational," "interorganizational," "joint-venture," "joint venture," "buyer-supplier," "licensing," and "network." This approach is similar to that used by Parmigiani and Rivera-Santos (2011) and Lumineau and Oliveira (2018). Second, we manually selected relevant articles using the snowballing technique. Specifically, we checked the lists of references in the most relevant articles to identify articles we would have otherwise missed. Our systematic search in the Web of Science's "Management" category yielded 895 results. We identified 10 additional articles through snowballing. In order to identify the articles relevant for this study, we went through the entire list and screened each article's title and abstract to exclude articles outside our focus. With this procedure, we had an end result of 50 articles directly relevant to the study's purpose. After thoroughly reviewing these studies, we classified them according to the level at which the initial trigger for the disruption lies.

${ }^{2}$ As per the Standard Industrial Classification (SIC) Code 3824, the veterinary drug field is considered a part of the pharmaceutical industry.

${ }^{3}$ Interviews were conducted face to face except for some follow-up interviews that were conducted by phone. 
${ }^{4}$ We are confident that we reached empirical saturation. In contrast to complex multipoint partnerships (Doz 1996), which span various business units and usually involve multiple projects, R\&D alliances like the one under investigation typically involve only a relatively small number of individuals. It is thus unlikely that more interviews would have led to a better or more complete understanding of the issues under scrutiny.

${ }^{5}$ Although studying alliance governance formation, evolution, and adjustment processes in a nonretrospective manner (Ariño and Ring 2010, Lumineau et al. 2011, Brattström and Faems 2020) has some advantages, we purposefully selected (ex post) a revelatory case that had been subject to instructive governance dynamics (i.e., disruption and subsequent adjustment) over time. In addition, studying choices, the impact and adaptions of alliance governance mechanisms in real time represents a delicate challenge (Doz 1996, p. 58). It is difficult to maintain a legitimate presence in the field while not influencing the ongoing alliance governance dynamics-as, for instance, collaborating parties may be tempted to seek advice (e.g., in respect to contract design) and ask the researchers to step into the process at times. Therefore, we believe that for the study's research purpose, the benefits of a retrospective approach largely outweigh the potential overall disadvantages.

${ }^{6}$ In identifying these major decisive points, we followed Ring and Van de Ven (1994), who define them "as critical incidents when parties engage in actions related to the development of their relationship" (p. 112).

${ }^{7}$ Our notion of value relates to the quality of a specific governance mechanism of being useful and thus encompasses both dimensions of efficiency and effectiveness.

${ }^{8}$ Although alliance governance research generally does not distinguish between the formality and informality of a contractual agreement-assuming implicitly that all contracts are formal-the distinction between formal and informal contracts is, in fact, common practice in law. Notably, contract law that deals with "the formation and enforcement of agreements between parties" (Cross and Miller 2012, p. 184) stresses that an "agreement does not necessarily have to be in writing" (Cross and Miller 2012, p. 190) and that "in most cases, an oral contract is binding and enforceable" (Mann and Roberts 2018 , p. 175). In contrast to a formal contract "which is legally binding because of its particular form or mode of expression" (Smith et al. 1993, p. 191), in an informal contract, terms and promises are expressed orally instead of in written words (see Barnes et al. 2009, p. 175, Mann and Roberts 2018, p. 178). As such, a valid contract (i.e., a legally binding agreement) must not necessarily be in writing to be enforceable in court. Cross and Miller (2012), for instance, note that "contracts are usually based on their substance rather than their form" (p. 189). In other words, a contract does not generally require a special method of creation nor depend on a specific kind of form (notably written text) for its legal validity.

\section{References}

Abdi M, Aulakh PS (2017) Locus of uncertainty and the relationship between contractual and relational governance in cross-border interfirm relationships. J. Management 43(3):771-803.

Achrol RS, Gundlach GT (1999) Legal and social safeguards against opportunism in exchange. J. Retailing 75(1):107-124.

Alimadadi S, Bengtson A, Salmi A (2019) Disruption, dissolution and reconstruction: A dialectical view on inter-organizational relationship development. Scandanavian J. Management 35(3):1-13.

Argyres NS, Mayer KJ (2007) Contract design as firm capability: An integration of learning and transaction cost perspectives. Acad. Management Rev. 32(4):1060-1077.

Ariño A, de la Torre J (1998) Learning from failure: Toward an evolutionary model of collaborative ventures. Organ. Sci. 9(3): 306-325.
Ariño A, Ring PS (2010) The role of fairness in alliance formation. Strategic Management J. 31(10):1054-1087.

Ariño A, Reuer JJ, Mayer KJ, Jané J (2014) Contracts, negotiation, and learning: An examination of termination provisions. J. Management Stud. 51(3):379-405.

Arslan B, Tarakci M (2020) Negative spillovers across partnerships for responsible innovation: Evidence from the 2014 Ebola outbreak. J. Management Stud., ePub ahead of print May 29, https:// doi.org/10.1111/joms.12607.

Bakker RM (2016) Stepping in and stepping out: Strategic alliance partner reconfiguration and the unplanned termination of complex projects. Strategic Management J. 37(9):1919-1941.

Barnes AJ, Dworkin TM, Richards EL (2009) Law for Business, 10th ed. (McGraw-Hill, Irwin, NY).

Bendapudi N, Leone RP (2002) Managing business-to-business customer relationships following key contact employee turnover in a vendor firm. J. Marketing 66(2):83-101.

Berends H, Sydow J (2020) Process view on inter-organizational collaborations. Res. Sociol. Organ. 64:1-16.

Berends H, van Burg E, van Raaij EM (2011) Contacts and contracts: Cross-level network dynamics in the development of an aircraft material.Organ. Sci. 22(4):940-960.

Bode C, Wagner SM, Petersen KJ, Ellram LM (2011) Understanding responses to supply chain disruptions: Insights from information processing and resource dependence perspectives. Acad. Management J. 54(4):833-856.

Bradach JL (1997) Using the plural form in the management of restaurant chains. Admin. Sci. Quart. 42(2):276-303.

Brattström A, Faems D (2020) Interorganizational relationships as political battlefields: How fragmentation within organizations shapes relational dynamics between organizations. Acad. Management J. 63(5):1591-1620.

Brattström A, Faems D, Mähring M (2018) From trust convergence to trust divergence: Trust development in conflictual interorganizational relationships.Organ. Stud. 40(11):1685-1711.

Bruyaka O, Philippe D, Castañer X (2018) Run away or stick together? The impact of organization-specific events on alliance partner defection. Acad. Management Rev. 43(3):445-469.

Busse C, Kach AP, Wagner SM (2017) Boundary conditions: What they are, how to explore them, why we need them, and when to consider them. Organ. Res. Methods 20(4):574-609.

Cannon JP, Achrol RS, Gundlach GT (2000) Contracts, norms, and plural form governance. J. Acad. Marketing Sci. 28(2):180-194.

Cao Z, Lumineau F (2015) Revisiting the interplay between contractual and relational governance: A qualitative and metaanalytic investigation. J. Oper. Management 33-34:15-42.

Carson SJ, Madhok A, Wu T (2006) Uncertainty, opportunism, and governance: The effects of volatility and ambiguity on formal and relational contracting. Acad. Management J. 49(5): 1058-1077.

Chen-Wishart M (2012) Contract Law, 4th ed. (Oxford University Press, Oxford, UK).

Cross FB, Miller RL (2012) The Legal Environment of Business: Text and Cases, 8th ed. (South-Western, Cengage Learning, Mason, $\mathrm{OH}$ ).

Das TK, Teng B-S (1998) Between trust and control: Developing confidence in partner cooperation in alliances. Acad. Management Rev. 23(3):491-512.

Das TK, Teng B-S (2000) Instabilities of strategic alliances: An internal tensions perspective. Organ. Sci. 11(1):77-101.

Das TK, Teng B-S (2002) The dynamics of alliance conditions in the alliance development process. J. Management Stud. 39(5):725-746.

de Rond M, Bouchikhi H (2004) On the dialectics of strategic alliances. Organ. Sci. 15(1):56-69.

Doz YL (1996) The evolution of cooperation in strategic alliances: Initial conditions or learning processes? Strategic Management J. 17:55-83. 
Dyer JH, Singh H (1998) The relational view: Cooperative strategy and sources of interorganizational competitive advantage. Acad. Management Rev. 23(4):660-679.

Eisenhardt KM (1989) Building theories from case study research. Acad. Management Rev. 14(4):532-550.

Eisenhardt KM, Graebner ME (2007) Theory building from cases: Opportunities and challenges. Acad. Management J. 50(1):25-32.

Faems D, Janssens M, Madhok A, Van Looy B (2008) Toward an integrative perspective on alliance governance: Connecting contract design, trust dynamics, and contract application. Acad. Management J. 51(6):1053-1078.

Furmston M, Tolhurst GJ (2016) Contract Formation: Law and Practice, 2nd ed. (Oxford University Press, Oxford, UK).

Ghoshal S, Moran P (1996) Bad for practice: A critique of the transaction cost theory. Acad. Management Rev. 21(1):13-47.

Gibbert M, Ruigrok W, Wicki B (2008) What passes as a rigorous case study? Strategic Management J. 29(13):1465-1474.

Gillespie N, Dietz G (2009) Trust repair after an organization-level failure. Acad. Management J. 34(1):127-145.

Golden BR (1992) The past is the past-or is it? The use of retrospective accounts as indicators of past strategy. Acad. Management J. 35(4):848-860.

Gulati R, Sytch M (2008) Does familiarity breed trust? Revisiting the antecedents of trust. Management Decision Econom. 29(2-3): 165-190.

Gulati R, Wohlgezogen F, Zhelyazkov P (2012) The two facets of collaboration: Cooperation and coordination in strategic alliances. Acad. Management Ann. 6(1):531-583.

Handley SM, Angst CM (2015) The impact of culture on the relationship between governance and opportunism in outsourcing relationships. Strategic Management J. 36(9):1412-1434.

Harmon DJ, Kim PH, Mayer KJ (2015) Breaking the letter vs. spirit of the law: How the interpretation of contract violations affects trust and the management of relationships. Strategic Management J. 36(4):497-517.

Henderson R, Cockburn I (1994) Measuring competence? Exploring firm effects in pharmaceutical research. Strategic Management J. 15(1):63-84.

Hoetker G, Mellewigt T (2009) Choice and performance of governance mechanisms: Matching alliance governance to asset type. Strategic Management J. 30(10):1025-1044.

Howard M, Roehrich J, Lewis MA, Squire B (2019) Converging and diverging governance mechanisms: The role of (dys)function in long-term interorganizational relationships. British J. Management 30(3):624-644.

Huber TL, Fischer TA, Dibbern J, Hirschheim R (2013) A process model of complementarity and substitution of contractual and relational governance in IS outsourcing. J. Management Inform. Systems 30(3):81-114.

Inkpen AC, Beamish PW (1997) Knowledge, bargaining power, and the instability of international joint ventures. Acad. Management Rev. 22(1):177-202.

Kale P, Singh H (2009) Managing strategic alliances: What do we know now, and where do we go from here? Acad. Management Perspective 23(3):45-62.

Klein Woolthuis R, Hillebrand B, Nooteboom B (2005) Trust, contract and relationship development. Organ. Stud. 26(6):813-840.

Koza MP, Lewin AY (1998) The co-evolution of strategic alliances. Organ. Sci. 9(3):255-264.

Kramer RM, Lewicki R (2010) Repairing trust and enhancing trust: Approaches to reducing organizational trust deficits. Acad. Management Ann. 4(1):245-277.

Langley A (1999) Strategies for theorizing from process data. Acad. Management Rev. 24(4):691-710.

Langley A (2007) Process thinking in strategic organization. Strategic Organ. 5(3):271-282.
Langley A, Smallman C, Tsoukas H, Van de Ven AH (2013) Process studies of change in organization and management: Unveiling temporality, activity, and flow. Acad. Management J. 56(1):1-13.

Laursen K, Moreira S, Reichstein T, Leone MI (2017) Evading the boomerang effect: Using the grant-back clause to further generative appropriability from technology licensing deals. Organ. Sci. 28(3):514-530.

Lavie D, Haunschild PR, Khanna P (2012) Organizational differences, relational mechanisms, and alliance performance. Strategic Management J. 33(13):1453-1479.

Li JJ, Poppo L, Zhou KZ (2010) Relational mechanisms, formal contracts, and local knowledge acquisition by international subsidiaries. Strategic Management J. 31(4):349-370.

Liu Y, Luo Y, Liu T (2009) Governing buyer-supplier relationships through transactional and relational mechanisms: Evidence from China. J. Oper. Management 27(4):294-309.

Lui SS, Ngo H-Y (2004) The role of trust and contractual safeguards on cooperation in non-equity alliances. J. Management 30(4): $471-485$.

Lui SS, Ngo H-Y (2005) An action pattern model of inter-firm cooperation. J. Management Stud. 42(6):1123-1153.

Lumineau F (2017) How contracts influence trust and distrust. J. Management 43(5):1553-1577.

Lumineau F, Malhotra D (2011) Shadow of the contract: How contract structure shapes interfirm dispute resolution. Strategic Management J. 32(5):532-555.

Lumineau F, Oliveira N (2018) A pluralistic perspective to overcome major blind spots in research on interorganizational relationships. Acad. Management Ann. 12(1):440-465.

Lumineau F, Fréchet M, Puthod D (2011) An organizational learning perspective on the contracting process. Strategic Organ. 9(1):8-32.

Lumineau F, Wang W, Schilke O (2020) Blockchain governance-A new way of organizing collaborations? Organ. Sci., ePub ahead of print October 9, https://doi.org/10.1287/orsc.2020.1379.

Lusch RF, Brown JR (1996) Interdependency, contracting, and relational behavior in marketing channels. J. Marketing 60(4):19-38

Macaulay S (1963) Non-contractual relations in business: A preliminary study. Am. Sociol. Rev. 28(1):55-67.

Macneil IR (1978) Contracts: Adjustment of long-term economic relations under classical, neoclassical, and relational contract law. Northwestern University Law Rev. 72(6):854-902.

Macneil IR (1980) The New Social Contract: An Inquiry into Modern Contractual Relations (Yale University Press, New Haven, CT).

Madhavan R, Koka BR, Prescott JE (1998) Network in transition: How industry events (re)shape interfirm relationships. Strategic Management J. 19(5):439-459.

Majchrzak A, Jarvenpaa SL, Bagherzadeh M (2015) A review of interorganizational collaboration dynamics. J. Management 41(5): $1338-1360$.

Malhotra D, Lumineau F (2011) Trust and collaboration in the aftermath of conflict: The effects of contract structure. Acad. Management J. 54(5):981-998.

Malhotra D, Murnighan JK (2002) The effects of contracts on interpersonal trust. Admin. Sci. Quart. 47(3):534-559.

Mann RA, Roberts BS (2018) Smith E Roberson's Business Law, 17th ed. (Cengage Learning, Boston, MA).

Mayer KJ, Argyres NS (2004) Learning to contract: Evidence from the personal computer industry. Organ. Sci. 15(4):394-410.

McEvily B, Soda G, Tortoriello M (2014) More formally: Rediscovering the missing link between formal organization and informal social structure. Acad. Management Ann. 8(1):299-345.

Mesquita LF, Brush TH (2008) Untangling safeguard and production coordination effects in long-term buyer-supplier relationships. Acad. Management J. 51(4):785-807.

Miles MB, Huberman AM (1984) Qualitative Data Analysis: A Sourcebook of New Methods (Sage, Beverly Hills, CA). 
Montesquieu C (1989) The Spirit of the Laws (Cambridge University Press, Cambridge, UK).

Oliveira N, Lumineau F (2017) How coordination trajectories influence the performance of interorganizational project networks. Organ. Sci. 28(6):1029-1060.

Oxley JE (1999) Institutional environment and the mechanisms of governance: The impact of intellectual property protection on the structure of inter-firm alliances. J. Econom. Behav. Organ. 38(3):283-309.

Ozcan P, Han S, Graebner ME (2017) Single cases: The what, why, and how. Mir RA, Jain S, eds. The Routledge Companion to Qualitative Research in Organization Studies (Routledge, New York), 92-112.

Palmatier RW (2008) Interfirm relational drivers of customer value. J. Marketing 72(4):76-89.

Park SH, Ungson GR (2001) Interfirm rivalry and managerial complexity: A conceptual framework of alliance failure. Organ. Sci. 12(1):37-53.

Parmigiani A, Rivera-Santos M (2011) Clearing a path through the forest: A meta-review of interorganizational relationships. J. Management 37(4):1108-1136.

Pentland BT (1999) Building process theory with narrative: From description to explanation. Acad. Management Rev. 24(4): 711-724.

Poppo L, Cheng Z (2018) Trust and contracts: Complements vs. substitutes in business-to-business exchanges. Searle RH, Nienaber AMI, Sitkin SB, eds. The Routledge Companion to Trust (Routledge, London), 228-244.

Poppo L, Zenger T (2002) Do formal contracts and relational governance function as substitutes or complements? Strategic Management J. 23(8):707-725.

Poppo L, Zhou KZ (2014) Managing contracts for fairness in buyersupplier exchanges. Strategic Management J. 35(10):1508-1527.

Poppo L, Zhou KZ, Ryu S (2008) Alternative origins to interorganizational trust: An interdependence perspective on the shadow of the past and the shadow of the future. Organ. Sci. 19(1):39-55.

Reuer JJ, Ariño A (2002) Contractual renegotiations in strategic alliances. J. Management 28(1):47-68.

Reuer JJ, Ariño A (2007) Strategic alliance contracts: Dimensions and determinants of contractual complexity. Strategic Management J. 28(3):313-330.

Reuer JJ, Ariño A, Olk PM (2010) Entrepreneurial Alliances (Pearson, London).

Reuer JJ, Zollo M, Singh H (2002) Post-formation dynamics in strategic alliances. Strategic Management J. 23(2):135-151.

Reuer JJ, Ariño A, Poppo L, Zenger T (2016) Alliance governance. Strategic Management J. 37(13):37-44.

Ring PS (2002) The role of contracts in strategic alliances. Contractor F, Lorange P, eds. Cooperative Strategies and Strategic Alliances (Elsevier Science, London), 145-162.

Ring PS (2008) Theories of contract and their use in studying interorganizational relations: Sociological, psychological, economic, management, and legal. Cropper S, Huxham C, Ebers M, Ring PS, eds. Oxford Handbook of Inter-Organizational Relations (Oxford University Press, Oxford, UK), 1-24.

Ring PS, Van de Ven AH (1992) Structuring cooperative relationships between organizations. Strategic Management J. 13(7):483-498

Ring PS, Van de Ven AH (1994) Developmental processes of cooperative interorganizational relationships. Acad. Management Rev. 19(1):90-118.

Ryall MD, Sampson RC (2009) Formal contracts in the presence of relational enforcement mechanisms: Evidence from technology development projects. Management Sci. 55(6):906-925.

Sampson RC (2002) The role of lawyers in strategic alliances. Case Western Law Rev. 53:909-927.
Schepker DJ, Oh W-Y, Martynov A, Poppo L (2014) The many futures of contracts: Moving beyond structure and safeguarding to coordination and adaptation. J. Management 40(1):193-225.

Schilke O, Cook KS (2013) A cross-level process theory of trust development in interorganizational relationships. Strategic Organ. 11(3):281-303.

Schilke O, Cook KS (2015) Sources of alliance partner trustworthiness: Integrating calculative and relational perspectives. Strategic Management J. 36(2):276-297.

Schmitz C, Friess M, Alavi S, Habel J (2020) Understanding the impact of relationship disruptions. J. Marketing 84(1):66-87.

Siggelkow N (2002) Misperceiving interactions among complements and substitutes: Organizational consequences. Management Sci. 48(7):900-916.

Siggelkow N (2007) Persuasion with case studies. Acad. Management J. 50(1):20-24.

Sitkin SB, Roth NL (1993) Explaining the limited effectiveness of legalistic 'remedies' for trust/distrust. Organ. Sci. 4(3):367-392.

Smith LY, Mann RA, Roberts BS (1993) Business Law and the Regulation of Business, 4th ed. (West Publishing, St. Paul, MN).

Soda G, Zaheer A (2012) A network perspective on organizational architecture: Performance effects on the interplay of formal and informal organization. Strategic Management J. 33(6):751-771.

Telser LG (1980) A theory of self-enforcing agreements. J. Bus. 53(1):27-44.

Van de Ven AH, Walker G (1984) The dynamics of interorganizational coordination. Admin. Sci. Quart. 29(4):598-621.

Van Maanen J (1979) Reclaiming qualitative methods for organizational research: A preface. Admin. Sci. Quart. 24(4):520-526.

Vanneste BS, Puranam P (2010) Repeated interactions and contractual detail: Identifying the learning effect. Organ. Sci. 21(1):186-201.

Vanneste BS, Puranam P, Kretschmer T (2014) Trust over time in exchange relationships: Meta-analysis and theory. Strategic Management J. 35(12):1891-1902.

Vlaar PWL, Van den Bosch FAJ, Volberda HW (2007) Toward a dialectical perspective on formalization in interorganizational relationships: How alliance managers capitalize on the duality inherent in contracts, rules and procedures. Organ. Stud. 28(4):437-466.

Volberda HW (1998) Building the Flexible Firm (Oxford University Press, Oxford, UK).

Wang Q, Craighead CW, Li JJ (2014) Justice served: Mitigating damaged trust stemming from supply chain disruption. J. Oper. Management 32(6):374-386.

Williamson OE (1975) Markets and Hierarchies: Analysis and Antitrust Implications (Free Press, New York).

Williamson OE (1985) The Economic Institutions of Capitalism (Free Press, New York).

Yin RK (2014) Case Study Research: Design and Methods, 5th ed. (Sage, Los Angeles).

Zaheer A, McEvily B, Perrone V (1998) Does trust matter? Exploring the effects of interorganizational and interpersonal trust on performance. Organ. Sci. 9(2):141-159.

Zenger TR, Lazzarini SG, Poppo L (2002) Informal and formal organization in new institutional economics. Ingram $P$, Silverman $B$, eds. Advances in Strategic Management: The New Institutionalism in Strategic Management (JAI Press, Oxford, UK), 275-303.

Zhang C, Bai X, Gu FF (2018) Contract learning in the aftermath of exchange disruptions: An empirical study of renewing interfirm relationships. Industry Marketing Management 71:215-226.

Zhou KZ, Poppo L (2010) Exchange hazards, relational reliability, and contracts in China: The contingent role of legal enforceability. J. Internat. Bus. Stud. 41(5):861-881.

Zhou KZ, Xu D (2012) How foreign firms curtail local supplier opportunism in China: Detailed contracts, centralized control, and relational governance. J. Internat. Bus. Stud. 43(7):677-692. 
Zollo M, Reuer JJ, Singh H (2002) Interorganizational routines and performance in strategic alliances. Organ. Sci. 13(6):701-713.

Arne Keller is a postdoctoral researcher at the Johannes Kepler University Linz. He holds a PhD (Dr. rer. pol.) from Freie Universität Berlin. His research centers on processual and evolutionary dynamics of organizations and interorganizational relationships.

Fabrice Lumineau's a professor of strategic management at University of Hong Kong. He received his PhD from HEC Paris. His research interests include interorganizational partnerships, the interplay between contract and trust in collaborative strategies, blockchain governance, opportunism, and ethical issues.
Thomas Mellewigt holds the chair of strategic management at Freie Universität Berlin. His research focuses on the appropriate design and effective governance of strategic alliances and buyer-supplier relationships. Recently, he also became interested in the determinants of corporate wrongdoing.

Africa Ariño is a professor of strategic management and holder of the Joaquim Molins Figueras Chair of Strategic Alliances at IESE Business School, University of Navarra. She received her PhD from University of California, Los Angeles. Her research interests include the governance and management of interorganizational relationships, with particular emphasis on strategic alliance design and dynamics. 